\title{
ANNUAL TECHNICAL PROGRESS REPORT OF RADIOISOTOPE POWER SYSTEM MATERIALS PRODUCTION AND TECHNOLOGY PROGRAM TASKS FOR OCTOBER 1, 2004 THROUGH SEPTEMBER 30, 2005
}

Prepared for Department of Energy Office of Space and Defense Power Systems Under Budget and Reporting Classification

AF 011010 00, 400413 00, 400414 00, 40041600 , and 400403305

by

Radioisotope Power System Program Materials Science and Technology Division Oak Ridge National Laboratory

Oak Ridge National Laboratory

Oak Ridge, Tennessee 37831-6080

Operated by UT-Battelle, LLC for the

U. S. Department of Energy

Contract DE-AC05-00OR22725 


\section{CONTENTS}

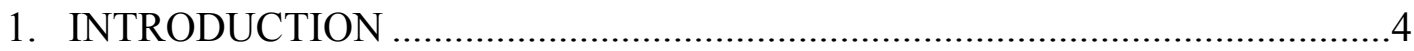

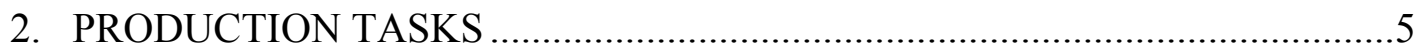

2.1 CARBON-BONDED CARBON FIBER .............................................5

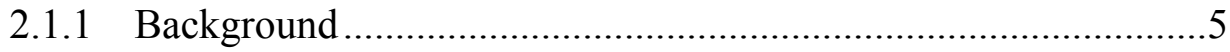

2.1.2 CBCF Production in Fiscal Year 2005 ......................................5

2.1.3 Qualification of New Production FWPF....................................5

2.1.4 5D FWPF - A Candidate Aeroshell Material for the GPHS ........6

2.2 IRIDIUM ALLOY BLANK AND FOIL PRODUCTION ........................7

2.2.1 Iridium Powder Procurement and Certification.......................... 7

2.2.2 Blank Production ................................................................

2.2.2.1 Blank Production from G6 Ingot ..................................

2.2.2.2 Blank Production from G8 Ingot .................................8

2.2.2.3 Blank Production from K1 Ingot ................................ 8

2.2.2.4 Blank Production from K2 Ingot ................................9

2.2.2.5 Blank Production from GR9 Ingot................................9

2.2.2.6 Blank Production from K3 Ingot ................................10

2.2.3 Transfers of Materials to CVS Production Task.........................10

2.2.4 Training ......................................................................... 10

2.2.5 Production Equipment .......................................................11

2.2.6 Trend Analysis for Iridium Alloy Blank and Foil Production....11

2.2.6.1 Trending of Chemical Analysis Results .......................11

2.2.6.2 Trend Analysis of Dimensional Measurements ..............14

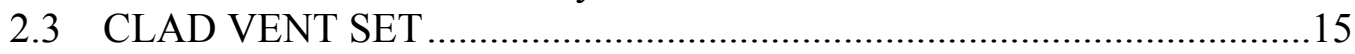

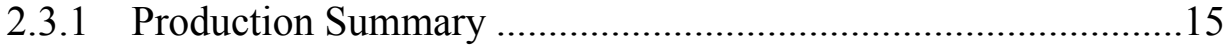

2.3.2 Personnel Training .................................................................15

2.3.3 Shield Cup Assembly Evaluation .............................................15

2.3.4 High Temperature Vacuum Furnace Upgrades ........................16

2.3.5 Tooling Maintenance/Evaluations ..........................................17

2.3.6 Frit Vent Assembly Power and Foil Evaluations......................17

2.3.7 Cup Second-Form Die Evaluation ..............................................18

2.3.8 Deviation Request and Nonconformance Report Summaries ....19

2.3.9 Production Summaries ...............................................................19

2.4 IRIDIUM POWDER AND INVENTORY MANAGEMENT ..................20

2.4.1 Iridium Demand and Supply Schedule ....................................20

2.4.2 Annual Write-Off...................................................................21

2.4.3 Iridium Accountability Reviews ..........................................21

2.4.4 Shipment of Iridium ..............................................................22

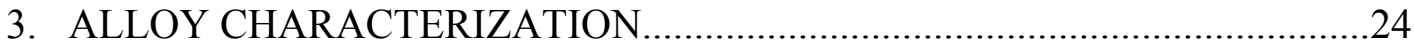

3.1 TENSILE BEHAVIOR OF Ta-10W ...........................................24

3.1.1 Introduction.................................................................24

3.1.2 Effect of Grain Size on the Low-Temperature Tensile Ductility of DOP-26 Iridium................................................24

3.1.3 Mechanical Properties of Haynes Alloy 25 .............................24

3.1.4 Compatibility of Haynes Alloy 25 with Graphite......................25 
3.1.5 Effects of Oxygen on the Impact Ductility of Ta-10W

3.1.6 Effect of Copper on the Impact Ductility of DOP-26 Iridium

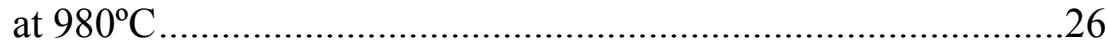

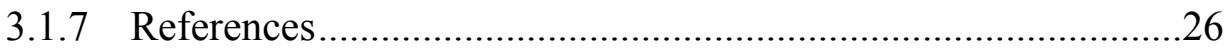

3.2 ORNL CHARACTERIZATION OF MIN-K TE-1400 .............................27

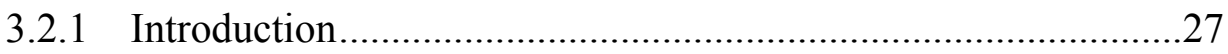

3.2.2 Experimental Procedures ........................................................27

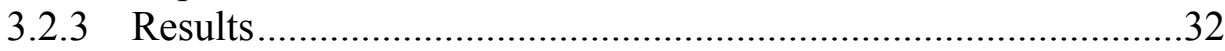

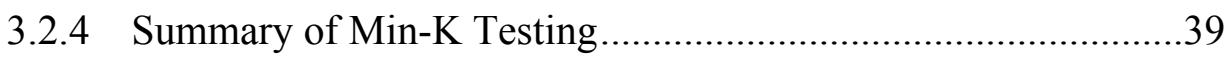




\subsection{INTRODUCTION}

The Office of Space and Defense Power Systems of the Department of Energy (DOE) provides Radioisotope Power Systems (RPS) for applications where conventional power systems are not feasible. For example, radioisotope thermoelectric generators were supplied by the DOE to the National Aeronautics and Space Administration for deep space missions including the Cassini Mission launched in October of 1997 to study the planet Saturn. For the Cassini Mission, ORNL produced carbon-bonded carbon fiber $(\mathrm{CBCF})$ insulator sets, iridium alloy blanks and foil, and clad vent sets (CVS) used in the generators. The Oak Ridge National Laboratory (ORNL) has been involved in developing materials and technology and producing components for the DOE for more than three decades.

This report reflects program guidance from the Office of Space and Defense Power Systems for fiscal year (FY) 2005. Production activities for prime quality (prime) CBCF insulator sets, iridium alloy blanks and foil, and CVS are summarized in this report. Technology activities are also reported that were conducted to improve the manufacturing processes, characterize materials, or to develop information for new radioisotope power systems. 


\subsection{PRODUCTION TASKS}

\subsection{CARBON-BONDED CARBON FIBER}

\subsubsection{Background}

The Carbon-Bonded Carbon Fiber (CBCF) production facilities have been operated in a production maintenance mode since the Cassini campaign to produce prime insulators. Dedicated facilities for CBCF production remain in the Carbon Materials Technology Laboratory at ORNL. During much of the 1990s CBCF production was directed at making experimental variations of CBCF that explored the potential for improved insulating attributes at very high temperatures. CBCF sleeves produced in FY 2000 were the first to be fully characterized as prime in nearly a decade. Issues related to elevated impurities in $\mathrm{CBCF}$ were resolved and production of prime insulators continued in FY 2003 and FY 2004.

\subsubsection{CBCF Production in FY 2005}

More than twenty-four additional prime CBCF insulation sets were produced in FY 2005. Numerous Quality Assurance Surveillances were conducted including: Instrument Calibration, Personnel Training and Slurry Molding of Insulators. Renovation of the CBCF Laboratory was initiated in the fourth quarter. Within the $\mathrm{CBCF}$ effort, the subtask manager contributed to preliminary plans for the qualification of new production Fine Weave Pierced Fabric (FWPF). Efforts to identify improved carbon-carbon composites for the GPHS continued with a preliminary assessment of 5D FWPF.

\subsubsection{Qualification of New Production FWPF}

The DOE Office of Space and Defense Power has committed to the procurement of new billets of FWPF carbon-carbon composite from Textron Systems. These new billets will be produced from nominally the same raw materials used in the current lot of billets produced in 1991-92. Although the HMU carbon fiber is out of commercial production, Hexcel has agreed to produce a limited quantity at their R\&T Technology Pilot Line in Salt Lake City, UT. Polyacrylonitrile (PAN) precursor fibers for HMU carbon fiber will be produced in Hexcel's Decatur, Alabama plant. This PAN precursor may be somewhat superior to the historic material in terms of chemical purity and lower defect population. Densification processing will be carried out using $15 \mathrm{~V}$ coal Tar Pitch produced by Reilly Industries. 15V Coal Tar Pitch is a distillate of coal tar from a particular battery of metallurgical coke ovens operated by Detroit Edison for US Steel's Great Lakes Division. This facility was the identical source of 15V Pitch used for the 1991-1992 production of FWPF. It appears reasonable to expect a high level of similitude between raw materials used for the near-term production of FWPF and that used in the previous campaign. The expertise and facilities to be engaged in the near term production of Textron FWPF further supports an expectation that the resulting material will be comparable to the historic material.

An assessment was made to define the role ORNL could play in supporting a qualification program for new production FWPF. This effort would include: density measurements, mechanical properties tests, ash analysis, and chemical impurity analysis. ORNL has extensive experience in determining the thermal conductivity of carbon materials including; $\mathrm{CBCF}$, graphite and carbon-carbon composites. ORNL uses the Laser Flash Method for thermal diffusivity measurement. With the corresponding heat capacity data, thermal conductivity is directly calculated. 
A number of tests have been specified to qualify new production FWPF and establish equivalence to the historic material. Some of these tests offer additional opportunity to establish the equivalence of the old and new material. Mechanical properties tests that require specimens of considerable volume will be compared to the historic data based on a strict adherence to standard test methods that were previously used for characterization. The similarity of new and old mechanical test results can be rigorously established. Chemical analysis and thermophysical properties measurements can be more sensitive to testing and analysis methods. Fortunately, many of these tests require a specimen of small volume. This provides an opportunity to test additional specimens of the old FWPF in parallel with testing new production material. Specimens can be taken from residual pieces of old production FWPF as prime hardware is machined for near term use. The specimen sectioning plan for the six qualification billets allows for additional small volume specimens. New production FWPF can be compared to the historical material by making back-to-back measurements of a few key properties using the same specimen geometry, characterized on the same apparatus, using the same procedure and operator, analyzed by the same method, and in the same time frame for both materials. These bridging tests can link new data with the old data thereby providing a stronger basis for establishing equivalence.

\subsubsection{D FWPF - A Candidate Aeroshell Material for the GPHS}

Recognizing the stringent requirements for the design and qualification of a system that must be capable of protecting the $\mathrm{PuO}_{2}$ fueled clad in the unlikely event of reentry, an alternative material that represents a conservative evolution of the current approach is more likely to gain acceptance than one that embodies dramatic changes. Textron Systems could offer a 5D-FWPF material that represents a minor variation on the architecture of the currently specified 3D-FWPF material. By rotating alternate woven layers by $45^{\circ}$, the final composite will have four directions of in-plane carbon fiber reinforcement (5 directions total, including the $\mathrm{Z}$ reinforcement) and, consequently, more isotropic properties. Textron produced and characterized three billets of 5D-FWPF in support of an Air Force development effort in the early 1980's. The results of mechanical properties tests indicated that the 5D-FWPF exhibited significantly greater shear strength and modulus over the conventional FWPF material. The on-axis strengths and moduli of 5D-FWPF are comparable to $3 \mathrm{D}-\mathrm{FWPF}$. The $45^{\circ}$ compressive strength and modulus was also notably higher. Differences can be accounted for by yarn volume fraction considerations.

Although impact performance of 5D-FWPF has not been assessed by numerical simulation or component tests, the improvement in some mechanical properties suggests the potential for improvement over the conventional 3D-FWPF material. Impact tests on fueled GPHS modules made of 3D FWPF exhibited failure of the graphite impact shell (GIS) at the four $45^{\circ}$ weak material planes. Significant distortion of the fueled clads were typically observed. The increase in minimum strengths for all in-plane directions for the 5D-FWPF would increase the circumferential strength of the GIS thereby providing greater constraint for the fuel during impact. Impact-tested Aeroshells also exhibited localized failure along weak material planes. An increase in minimum strength material directions results in localized loads being distributed over a greater material volume, thereby enhancing energy absorption in the composite. When a higher level of mechanical energy is absorbed by the Aeroshell and GIS during impact, less energy is partitioned into the fuel. 5D-FWPF is an excellent candidate for improving the Aeroshell and GIS material. The manufacturability has been demonstrated and preliminary characterization has been completed. Numerical simulations by Orbital Sciences Corporation are needed to quantify the potential for improved impact performance. 


\subsection{IRIDIUM ALLOY BLANK AND FOIL PRODUCTION}

The goals for this activity are to produce prime blanks and foil under full configuration control, maintain production capability and to supply materials needed for clad vent set demonstration and maintenance activities. During FY 2005 a total of 307 prime blanks were transferred to the CVS task. A total of $48 \mathrm{~kg}$ of iridium powder was qualified and blended to produce the L-batch of powder. A technician apprentice was hired and trained in cleaning and rolling of iridium materials. A vacuum-annealing furnace was obtained from another Oak Ridge site and a new hot zone received for installation in the furnace. A purchase order was issued for a new rolling mill.

\subsubsection{Iridium Powder Procurement and Certification}

The L-batch of powder with a total weight of $48 \mathrm{~kg}$ was blended in July and August 2005. The powder consisted of $36 \mathrm{~kg}$ of powder purchased in August 2004, an additional $9 \mathrm{~kg}$ purchased in FY 2003, and also $3 \mathrm{~kg}$ purchased by another program to replace borrowed iridium. A total of $15 \mathrm{~kg}$ of the powder received in August 2004 was found nonconforming and returned for replacement. An additional $1.5 \mathrm{~kg}$ was found not conforming but was recommended for use as-is. This powder was accepted for use during FY 2005.

The powder purchased in FY2003 initially showed carbon contents in the range of 54 to $67 \mathrm{ppm}$ as compared to a specified maximum of $50 \mathrm{ppm}$. Multiple repeat samples of the powder showed carbon contents of 20 to $25 \mathrm{ppm}$. The powder was accepted for use as-is under NCR-IRB\&F2151 in June 2004.

The $15 \mathrm{~kg}$ of powder to replace the returned powder was received in September 2004 and analyzed in October 2004. Only $6 \mathrm{~kg}$ of this powder was found to meet the specification when sampled and analyzed. A total of $9 \mathrm{~kg}$ was found to be nonconforming and was accepted for use as-is under NCR- IRB\&F -2152. Iridium powder Johnson Matthey Lot 0019852 jar 1A contained $55 \mu \mathrm{g} / \mathrm{g}(55 \mathrm{ppm})$ ruthenium $(\mathrm{Ru})$ as compared to a specified maximum concentration of $50 \mu \mathrm{g} / \mathrm{g}$. Iridium powder Johnson Matthey Lot 0019852 jar 1B contained $110 \mu \mathrm{g} / \mathrm{g}(110 \mathrm{ppm})$ sodium $(\mathrm{Na})$ as compared to a specified maximum concentration of $100 \mu \mathrm{g} / \mathrm{g}$. Iridium powder Impala Lot 2003/31A1 jar 2 contained $78 \mu \mathrm{g} / \mathrm{g}(78 \mathrm{ppm})$ rhodium ( $\mathrm{Rh}$ ) as compared to a specified maximum concentration of $70 \mu \mathrm{g} / \mathrm{g}$. Each of the three jars contained about $3 \mathrm{~kg}$ of powder.

An additional $3 \mathrm{~kg}$ of powder was purchased during FY 2004 using funds from another program. This powder was in exchange for iridium alloy scrap material provided to that program. The material was found to contain $62 \mu \mathrm{g} / \mathrm{g}$ of $\mathrm{Ru}$ as compared to the specification requirement of 50 $\mu \mathrm{g} / \mathrm{g}$ maximum. This powder was accepted for use as-is under NCR IRB\&F 2150.

Iridium powder Anglo Lot 0011 jar 2 received in August 2004 was found to contain 137 ppm rhodium (Rh) as compared to a specified maximum concentration of $70 \mathrm{ppm}$. The jar containing about $1.5 \mathrm{~kg}$ of powder was accepted for use as-is under NCR IRB\&F 2153 in November 2004.

\subsubsection{Blank Production}

\subsubsection{Blank Production from G6 Ingot}

The G6 ingot was processed to produce blanks in FY 2004. Chemical and metallographic analyses of samples from the G6 ingot were successfully completed in November 2005. Nondestructive testing of blanks from G6 ingot was completed. A total of 84 prime blanks from 
G6 ingot were transferred to the CVS task with approved data packages on November 15, 2004. Nonconformance reports were approved for seven additional blanks for use as-is. Four blanks had minimum thickness of $0.62 \mathrm{~mm}$ as compared to the specified $0.63 \mathrm{~mm}$ and three blanks had identifying scribe marks on the wrong side of the blank. The seven blanks were transferred to the CVS task with an approved data package on January 3, 2005. One blank was reworked and transferred with an approved data package on May 3, 2005.

\subsubsection{Blank Production from G8 Ingot}

The G8 ingot, extruded in the previous year, was processed to produce blanks. The molybdenum can was chemically removed from the G8 extruded bar. A total of 17 rolled sheets were prepared from the extruded bar. A total of 113 blanks were electro-discharge machined from these sheets and ground to final thickness. All but one of these blanks passed dimensional inspection. A total of 103 blanks from ingot G8 passed ultrasonic inspection. All but one of the ten which did not pass were from the tail of the extruded bar. Two of these blanks were designated for weldability testing, one for tensile impact testing, and the remaining seven transferred to the Alloy Characterization Task for use in measurement of tensile elongation as a function of impact test temperature. All blanks passed dye penetrant inspection. A total of 6 blanks were reworked by sanding to remove indications of visual indications of defects in accordance with approved procedures. The reworked blanks passed all inspections. Metallographic inspections were successfully completed. Carbon and oxygen analyses were also completed with normal results.

Glow discharge mass spectrometry (GDMS) analysis was performed on one sample from each pair of adjacent sheets. The results showed the sample from sheet G8-2 to have aluminum content of $85 \mathrm{ppm}$ as compared to a specified limit of 80-ppm max. An NCR (IRB\&F-2157) was issued for the 14 blanks from sheets G8-2 and G8-3 and repeat analyses were made on three additional samples for sheets G8-2 and G8-3. GDMS of the sample from sheet G8-13 showed a silicon content of $25 \mathrm{ppm}$, which is below the specified limit of $50 \mathrm{ppm}$, but still of concern. Five additional GDMS samples from sheets G8-12, G8-13 and G8-14 were submitted for analysis. The remaining GDMS samples showed normal chemical analyses.

NCR IRB\&F 2157 for seven blanks from sheet G8-2 was approved with recommendation for use as-is based on the results of the repeat GDMS analyses. Three repeat analyses showed normal aluminum levels of $57 \mathrm{ppm}$ for sheets G8-2 and G8-3. Also, the five additional GDMS samples from sheets G8-12, G8-13 and G8-14 showed 2 ppm silicon or less.

A total of 26 blanks from sheets G8-1, $-4,-5,-15$ and -16 were transferred to the CVS task with approved data packages on February 8, 2005. A total of 24 blanks from sheets G8-3, -12, 13, and -14 were transferred to the CVS task with approved data packages on February 21, 2005. A total of 40 blanks from sheets G8-6 through G8-11 were transferred to the CVS task with approved data packages on February 28, 2005. A total of 13 blanks from G8 ingot were transferred to the CVS task with approved data packages on May 3, 2005. These included both reworked blanks and blanks with nonconformance reports approved for use as-is.

\subsubsection{Blank Production from K1 Ingot}

The K1 electrode was assembled by electron beam welding of electrode segments produced in FY 2004. The electrode was vacuum arc remelted to produce the K1 ingot. The ingot was placed in a molybdenum can and hot extruded. The extrusion can was removed and the extrusion sectioned and rolled to produce 18 sheets. A total of 119 blanks were electro-discharge machined from these sheets and ground. All of these blanks passed dimensional inspection. However, the 7 
blanks from $\mathrm{K} 1$ ingot sheet 18 were later found to have identifying scribe marks that were nonconforming. These were documented by NCR IRB\&F 2160, and the blanks were subsequently approved for use as-is. The blanks were cleaned and stress relieved. Ultrasonic inspection of the 119 blanks showed all but one passing this inspection. All blanks also passed dye penetrant inspection.

Visual inspection of blanks from $\mathrm{K} 1$ ingot yielded 44 acceptable blanks on the first inspection. A total of 69 blanks were reworked by sanding and cleaned. All of these reworked blanks passed dye penetrant and visual inspection and were acceptable for use. Scanning electron microscopy was performed to characterize the visual indications. The blank selected for evaluation showed eight visual indications. All had the appearance of chemical deposits on the surface of the blank, typically $0.04 \mathrm{~mm}$ in size. Six of the deposits contained aluminum with smaller amounts of other elements such as iron, potassium, and chlorine. One deposit, near the edge of the blank, contained nickel and chromium. Visual inspection of the reworked blanks following sanding and cleaning did not find any indications.

Chemical analysis and metallographic examination of samples from the $\mathrm{K} 1$ ingot were successfully completed. The one ultrasonic reject blank and two other acceptable blanks were selected for use in tensile impact testing, which is necessary for the qualification of the K-batch powder. The tensile impact testing of specimens for K-batch powder qualification was successfully completed. A total of 106 blanks from K1 ingot, with approved data packages, were transferred to the CVS task on June 23, 2005. An additional 7 blanks from sheet K1-18 were transferred to the CVS task with an approved data package on August 3, 2005.

\subsubsection{Blank Production from K2 Ingot}

The K2 ingot was fabricated and processed to blanks. A total of $17 \mathrm{~kg}$ of G-batch powder was prepared as six batch blends of about $2.9 \mathrm{~kg}$ each. The blended $\mathrm{Ir}-0.3 \% \mathrm{~W}$ powder was compacted, sintered in hydrogen gas, and vacuum outgassed. The compacts were electron-beam melted to produce 30 alloy buttons. The buttons were non-consumable arc melted in argon, alloyed with thorium and aluminum master alloy and drop-cast to produce DOP-26 alloy electrode segments with a total weight of $15 \mathrm{~kg}$. The segments were electron beam welded to produce the $\mathrm{K} 2$ electrode. The electrode was vacuum arc remelted to produce the K2 ingot. The ingot was placed in a molybdenum can and hot extruded. The extrusion can was removed and the extrusion sectioned and rolled to produce 18 sheets. A total of 111 blanks were electro-discharge machined from these sheets and ground. All but one blank passed dimensional inspection. The blanks were cleaned and stress relieved. Ultrasonic inspection of the 110 blanks showed all but one passing this inspection. All blanks also passed dye penetrant inspection. Metallography and chemical analysis of samples from K2 ingot were successfully completed.

\subsubsection{Blank Production from GR9 Ingot}

Processing of the GR9 ingot was initiated in order to produce blanks for delivery in FY 2006. A total of $14 \mathrm{~kg}$ of G-batch recycle material from the G5, G6 and G8 ingots was cleaned and prepared for melting. The material was button arc melted and drop-cast to produce electrode segments for the GR9 electrode. The segments were electron beam welded to produce the GR9 electrode. The arc melting of ingot GR9 was successfully completed. The ingot was cut to length and ground in preparation for extrusion. The GR9 ingot was successfully extruded. The extrusion was cut to produce rolling billets. These rolling billets were cleaned and hot rolling to produce sheets was initiated. 


\subsubsection{Blank Production from K3 Ingot}

Processing of the K3 ingot was initiated in order for an extruded bar to be stored as intermediate product for future production efforts. This replaces another stored extrusion used for blank production in FY 2004. A total of $17 \mathrm{~kg}$ of G-batch powder was prepared as six batch blends of about $2.9 \mathrm{~kg}$ each. The blended $\mathrm{Ir}-0.3 \% \mathrm{~W}$ powder was compacted, sintered in hydrogen gas, and vacuum outgassed. The compacts were electron-beam melted to produce 30 alloy buttons. The buttons were non-consumable arc melted in argon, alloyed with thorium and aluminum master alloy and drop-cast to produce DOP-26 alloy electrode segments with a total weight of 15 $\mathrm{kg}$. The segments were electron beam welded to produce the K3 electrode. The electrode was vacuum arc remelted to produce the K3 ingot. The ingot was placed in a molybdenum can and hot extruded. The extrusion can material was removed and the extrusion was stored.

\subsubsection{Transfers of Materials to CVS Production Task}

A total of 308 blanks from ingots G6, G8, and K18 were transferred to the CVS task in FY 2005. The transfers are summarized in Table 1.

\section{Table 1. Summary of Blanks Transferred to CVS task in FY 2005}

\begin{tabular}{|c|c|c|}
\hline Ingot & Date & Number \\
\hline \multirow[t]{4}{*}{ G6 } & $11 / 15 / 04$ & 84 \\
\hline & $1 / 3 / 05$ & 7 \\
\hline & $\underline{5 / 3 / 05}$ & 1 \\
\hline & subtotal & $\overline{92}$ \\
\hline \multirow[t]{5}{*}{ G8 } & $2 / 8 / 05$ & 26 \\
\hline & $2 / 21 / 05$ & 24 \\
\hline & $2 / 28 / 05$ & 40 \\
\hline & $\underline{5 / 3 / 05}$ & $\underline{13}$ \\
\hline & subtotal & $1 \overline{03}$ \\
\hline \multirow[t]{3}{*}{ K1 } & $6 / 23 / 05$ & 106 \\
\hline & $\underline{8 / 3 / 05}$ & 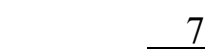 \\
\hline & subtotal & $\overline{113}$ \\
\hline
\end{tabular}

TOTAL

\subsubsection{Training}

A second technician apprentice was hired and trained in cleaning and rolling of iridium alloys. The apprentice is to replace a technician who is likely to retire within the next year. Six sheets from the scrap iridium alloy MS3 extrusion were rolled as part of the training of a technician apprentice. The sheets were stored for future use in training of personnel in the machining of iridium alloy blanks. The resulting blanks are expected to be suitable for experimental use. A second dimensional inspector was trained in the blank inspection procedure.

Alloying and drop-casting of electrode segments for the RS16 scrap iridium alloy electrode was performed to provide additional training. Trial vacuum arc remelting of the RS16 electrode in the Consarc furnace was successfully completed to verify operation of this furnace and produce the 
RS16 iridium alloy scrap ingot. The melted ingot was extruded and a portion of the extrusion machined to produce a spare electrode adapter to replace one destroyed during the melting of ingot GR7 in FY 2004.

Subsequently, the Consarc furnace was found to malfunction during the melt start sequence and the melting of iridium material was terminated. A replacement position transducer was installed and the system was returned to service following successful test melts of stainless steel materials.

\subsubsection{Production Equipment}

An existing vacuum annealing furnace located at the Oak Ridge East Tennessee Technology Park (K-25 site) was relocated to the Materials Processing group laboratory at ORNL. The furnace, purchased new in 1997 from the Brew Division of Thermal Technologies, Inc. has a hot zone size of $16 \times 16 \times 48$ inch. A new tungsten metal hot zone was purchased and installed in the furnace. It is planned that this will become the primary annealing furnace for iridium alloy blank and foil processing following qualification of the furnace.

A specification for a new $4 \mathrm{Hi} / 2 \mathrm{Hi}$ rolling mill was issued and a purchase order for this mill has been placed with Fenn Technologies. This will provide new equipment at a substantially lower cost than the two separate mills originally planned to replace old $2 \mathrm{Hi}$ and $4 \mathrm{Hi}$ mills. It will also greatly reduce need for floor space as compared to two separate mills. The specification provides for capability for quick roll changes. The building which houses the two existing mills is expected to be demolished within a few years and moving the existing mills is not practical due to their age (more than 50 years), condition, and contamination with PCB's.

\subsubsection{Trend Analysis for Iridium Alloy Blank and Foil Production}

\subsubsection{Trending of Chemical Analysis Results}

Chemical analysis for alloying elements and impurities, other than carbon and oxygen are performed by glow discharge mass spectrometry. Currently the analyses are performed by Shiva Technologies Inc. (Syracuse NY) in accordance with procedure MET-MatP-SOP-79. The procedure and the laboratory were approved by a deviation request (DR-Ir-206) on June 3, 2002. This procedure makes use of two reference materials supplied by ORNL and run with each group of up to ten test samples.

As a result of trend analysis reported in the FY 2004 annual report it was found that variations in specimen pin length had a significant effect on thorium results but not those of other elements. The deviation request DR-Ir-212, approved in October 2005, specified a pin length of $20.0 \pm 0.3$ $\mathrm{mm}$. This change was implemented in both the specimen preparation procedures and GDMS analysis procedure. All results reported during FY 2005 are for samples meeting this pin length requirement.

Five groups of samples were analyzed by GDMS for blank production in FY 2005. Two reference pins are run with each group of samples and used to correct the raw results for the alloying elements and important impurity elements. A standard pin from sheet G1-10 is used to correct for instrumental drift or variations. Corrected values for the alloying elements, aluminum, tungsten, and thorium are made by normalizing the results for the G1-10 reference pin to the nominal values of 50,3000, and $60 \mathrm{ppm}$, respectively in accordance with the standard procedure MET-MatP-SOP-79. Another reference pin taken from sheet RS10-9 is used to correct the values of certain important impurity elements. The results of analysis of the reference pins are listed in Table 2. The analyzed and corrected results for alloying elements for sheets from ingots G6, G8, $\mathrm{K} 1$ and $\mathrm{K} 2$ are shown in Table 3. 
The analyzed variation in tungsten contents shown in Table 3 is within the expected limits. The average corrected tungsten content for the 43 analyses of production material in FY 2005 is 2918 ppm. The standard deviation for all measurements is $128 \mathrm{ppm}$, equivalent to a relative standard deviation of $4.4 \%$.

Table 2. GDMS Analysis of Alloying Elements in Reference Pins Used for Correction of Sample Results

\begin{tabular}{lcccccc} 
& & \multicolumn{3}{c}{ ppm by weight } & \multicolumn{2}{c}{ ratio RS10-9/G1-10 } \\
job No. & sample ID & $\mathrm{Al}$ & $\mathrm{W}$ & $\mathrm{Th}$ & $\mathrm{Al}$ & $\mathrm{Th}$ \\
UN4022 & G1-10-22 & 68 & 3500 & 24 & 0.88 & 1.13 \\
& RS10-9-22 & 60 & 4000 & 27 & & \\
U00132 & G1-10-23 & 65 & 4400 & 35 & 0.78 & 0.89 \\
& RS10-9-23 & 51 & 4800 & 31 & & \\
U00446 & G1-10-24 & 80 & 4500 & 36 & 0.90 & \\
& RS10-9-24 & 72 & 4900 & 30 & & \\
U00915 & G1-10-24 & 75 & 4000 & 34 & 0.49 & \\
& RS10-9-24 & 37 & 4800 & 24 & & \\
UO2995 & G1-10-25 & 64 & 4400 & 36 & 0.86 & \\
& RS10-9-25 & 55 & 4600 & 27 & &
\end{tabular}

Table 3. Analysis of by GDMS of Samples From Production Ingots for

Blank Manufacture Corrected Bulk Composition, ppm By Weight

$\begin{array}{ccccc}\text { job No. } & \text { sample ID } & \text { Al } & \text { W } & \text { Th } \\ \text { UN4022 } & \text { G6-1-2 } & 61 & 2840 & 78 \\ & \text { G6-3-2 } & 64 & 3100 & 78 \\ & \text { G6-5-3 } & 54 & 2920 & 78 \\ & \text { G6-6-2 } & 57 & 3100 & 85 \\ & \text { G6-8 skel } & 50 & 3180 & 63 \\ & \text { G6-10-2 } & 51 & 3010 & 73 \\ & \text { G6-13-3 } & 49 & 2920 & 70 \\ \text { UO0132 } & \text { G6-15-1 } & 50 & 3100 & 70 \\ & \text { G8-1-1 } & 74 & 2860 & 73 \\ & \text { G8-4 } & 59 & 2920 & 70 \\ & \text { G8-7-1 } & 61 & 2860 & 70 \\ & \text { G8-9 } & 53 & 3060 & 68 \\ & \text { G8-11-1 } & 50 & 2860 & 68 \\ & \text { G8-13 } & 49 & 2990 & 68 \\ & \text { G8-15-1 } & 48 & 2860 & 65 \\ & \text { G8-17-1 } & 47 & 2990 & 63 \\ & \text { G8-2A } & 57 & 2810 & 63 \\ & \text { G8-2B } & 57 & 2810 & 68 \\ & \text { G8-3A } & 57 & 2750 & 61\end{array}$




$\begin{array}{ccccc} & \text { G8-12A } & 54 & 2880 & 70 \\ \text { G8-13A } & 53 & 2950 & 66 \\ \text { G8-13B } & 52 & 2880 & 66 \\ \text { G8-14A } & 53 & 2880 & 65 \\ \text { G8-14B } & 50 & 2810 & 63 \\ \text { K1-1c } & 28 & 2780 & 54 \\ \text { K1-4 } & 29 & 2850 & 52 \\ \text { K1-6 } & 29 & 2930 & 50 \\ \text { K1-7 } & 27 & 2930 & 50 \\ \text { K1-9a } & 29 & 2850 & 47 \\ \text { K1-11 } & 30 & 3230 & 52 \\ \text { K1-14 } & 29 & 3080 & 56 \\ \text { K1-16a } & 29 & 3080 & 56 \\ \text { K1-17a } & 28 & 3230 & 52 \\ \text { K2-1A } & 31 & 2790 & 54 \\ \text { K2-3 } & 39 & 2790 & 58 \\ \text { K2-5A } & 42 & 2790 & 61 \\ \text { K2-7A } & 43 & 2790 & 63 \\ \text { K2-10A } & 47 & 2790 & 65 \\ \text { K2-12A } & 49 & 2860 & 66 \\ \text { K2-14A } & 49 & 2860 & 63 \\ \text { K2-14A } & 49 & 2860 & 63 \\ \text { K2-16A } & 51 & 2790 & 65 \\ \text { K2-18 } & 52 & 2860 & 68\end{array}$

The analytical values obtained for aluminum and thorium are not entirely well behaved. In the case of the GDMS analysis of aluminum, the corrected values of 28 to $30 \mathrm{ppm}$ for the K1 samples (UO0915) are unusually low. These low values can be associated with an unusually large discrepancy in the reported values of aluminum in the standard pins used for this group of analyses. This is most clearly shown by a comparison of the ratio of aluminum in the standard pins (RS10-9/G1-10), which is 0.49 for this pair of reference pins, as compared to ratio values of 0.78 to 0.90 for the four other ratios of reference pin analyses. A "Grubb's test" at a 95\% confidence level indicates that the aluminum ratio for UO0915 is an outlier value. Also in this case the value of aluminum for the RS10-9 reference pin of $37 \mathrm{ppm}$ is substantially less than the average value for all RS10-9 reference pins of $60 \mathrm{ppm}$. One explanation is that some change in the analysis mechanism may have occurred following the analysis of the pin G1-10-24 affecting both the K1 samples and the RS10-9-24 reference pin which affected the aluminum analysis but apparently no other elements. Including all of the corrected aluminum analyses for FY 2005 production, with the exception of those for UO0915, the average of the 34 aluminum analyses is $51.8 \mathrm{ppm}$, with a standard deviation of $7.5 \mathrm{ppm}$ or a relative standard deviation of $15 \%$.

Similarly in the case of thorium, the corrected values of 63 to $85 \mathrm{ppm}$ for the G6 samples (UN4022) are unusually high. These high values are associated with an unusually large discrepancy in the reported values of thorium in the standard pins used for this group of analyses. The ratio of thorium in the standard pins (RS10-9/G1-10) is 1.13 for this pair of reference pins as compared to ratio values of 0.73 to 0.89 for the four other pairs of reference pin analyses. Also in this case the value of thorium for the G1-10-22 reference pin of $27 \mathrm{ppm}$ is substantially lower than the values in the range of 34 to $36 \mathrm{ppm}$ for the other four G1-10 reference pin measurements. A "Grubbs" test" at a 95\% confidence level indicates that the thorium measurement for the G1- 
10-22 reference pin is an outlier value. The low value of the thorium obtained for the G1-10-22 pin would be a direct cause for the unusually high corrected values for thorium in all of the pins from the G6 ingot. Including all of the corrected thorium analyses for FY 2005 production, with the exception of those for UN4022, the average of the 35 thorium analyses is $61.8 \mathrm{ppm}$, with a standard deviation of $6.9 \mathrm{ppm}$ or a relative standard deviation of $11 \%$.

A single nonconformance for chemistry occurred in FY 2005. The aluminum analysis for G8-2 on UO0132 was reported at $85 \mathrm{ppm}$ as compared to a specification limit of $80 \mathrm{ppm}$ maximum. The NCR IRB\&F-2157 was approved for use as-is on the basis of additional runs on samples G82A, G8-2B, and G8-3 listed in Table 3 for UO0446. Although the cause for the original measurement is not known it does not appear that reference pins used for correcting the measurement are the cause.

The recommendations for addressing the issue of reproducibility of aluminum and thorium analyses of the iridium alloy by glow discharge mass spectrometry are as follows:

1) Continue to monitor the analytical results for the reference materials.

2) Perform additional characterization of the uniformity of the reference materials.

3) Develop new reference materials to avoid depleting the limited quantities of the existing reference materials.

4) Evaluate possible changes to the procedure that would assure that analytical values of the reference materials are consistent prior to proceeding with analysis of production materials.

\subsubsection{Trend Analysis of Dimensional Measurements}

The results of the thickness inspections are listed in Table 4 for blanks either inspected or shipped during FY 2005. The ingots are listed in chronological order. The thickness is measured at a minimum of seven locations on each blank and a maximum and minimum value is reported. The distribution of the minimum thickness values is shown as the percentage of all blanks from the ingot at each increment of minimum thickness value from 0.62 to $0.68 \mathrm{~mm}$. The four blanks from ingot G6 with a minimum thickness of $0.62 \mathrm{~mm}$ were accepted for use as-is under NCR-IRB\&F2155. The experience in clad vent set (CVS) production favors having a narrow distribution of thickness values with the average thickness of $0.66 \mathrm{~mm}$ and minimum thickness values preferably of $0.65 \mathrm{~mm}$ or greater. The specification limit is 0.63 to $0.68 \mathrm{~mm}$ thickness.

The average of the thickness distribution for FY 2005 is also listed in Table 4 together with the average distribution for Cassini production. The results of thickness measurements for recent blanks are comparable to those for the Cassini production. There are relatively fewer blanks at 0.62 and $0.63 \mathrm{~mm}$ thickness and slightly more at 0.67 and $0.68 \mathrm{~mm}$ thickness. 
Table 4. Distribution of Minimum Thickness Values of Blanks by Ingot for Blanks Either Shipped or Inspected During FY 2005

\section{Percentage of Blanks With Listed Minimum Thickness, mm}

\begin{tabular}{cccccccc}
\hline & 0.62 & 0.63 & 0.64 & 0.65 & 0.66 & 0.67 & 0.68 \\
\hline G5 & 0 & 0 & 9 & 26 & 41 & 21 & 3 \\
G6 & 4 & 6 & 16 & 34 & 29 & 10 & 1 \\
G8 & 0 & 0 & 8 & 33 & 43 & 16 & 0 \\
K1 & 0 & 2 & 18 & 35 & 29 & 15 & 0 \\
K2 & 0 & 0 & 20 & 41 & 34 & 5 & 0 \\
Total & 0.6 & 1.3 & 13.4 & 32.6 & 36.5 & 14.5 & 1.0 \\
& & & & & & & \\
Cassini & 0.9 & 4.4 & 10.4 & 27.7 & 43.8 & 12.8 & 0.0 \\
\hline
\end{tabular}

\subsection{CLAD VENT SET}

\subsubsection{Production Summary}

One hundred twenty five prime and 11 engineering use (EU) Clad Vent Sets (CVS) were shipped to Los Alamos National Laboratory (LANL) in FY05. These included: 50 prime CVS shipped during the period of December 2004 and January 2005 for the National Aeronautics and Space Administration (NASA) Multi-Mission Radioisotope Thermoelectric Generator (MMRTG) program; another 40 prime CVS for the MMRTG mission shipped along with 4 EU long CVS; and 35 prime plus 7 EU CVS shipped in late August 2005 (15 prime CVS for the MMRTG program, 10 prime CVS for the Stirling Radioisotope Generator (SRG) program, and 10 prime plus 7 EU CVS for the DOE Production Maintenance program). An additional 34 prime CVS were stored by the end of FY05.

\subsubsection{Personnel Training}

Training of a back-up dimensional inspector was completed in mid FY05.

\subsubsection{Shield Cup Assembly Evaluation}

The ORNL shield cup assembly (SCA) production data through most of FY04 showed that the amount the weld shield extends above the cup open end face (surface -A-) had been to the low side of the 3.56/2.79 mm requirement. The average maximum and minimum values for the first 159 production units were $3.068 \mathrm{~mm}$ and $2.933 \mathrm{~mm}$, respectively. During FY04 the length of the weld shield alignment step on the weld shield tab-to-cup tooling was increased incrementally to put the weld shield length in the center of the drawing tolerance for each of the three production fixtures. The total alignment step depth increase ranged from 0.006 " to 0.009 " depending on the fixture and the specific location.

The average maximum and minimum values for the 172 production SCA welded since the final alignment step depth adjustments are $3.260 \mathrm{~mm}$ and $3.121 \mathrm{~mm}$, respectively. Most of these SCA were welded during FY05. The changes can be seen graphically in Chart 1 where the 172 values on the right side of the chart are much more centered between the specified $3.56 \mathrm{~mm}$ maximum and $2.79 \mathrm{~mm}$ minimum. Since the final tooling adjustments were completed only two assemblies 
or $1.2 \%$ had values outside the length from -A- requirement versus six assemblies or $2.9 \%$ prior to the adjustments. Table 5 indicates that the three production fixtures are yielding reasonably similar results - especially fixtures 2 and 3 . The Fixture 1 minimum length values are different than those for Fixtures 2 and 3, however, the maximum length values are similar. There is no clear explanation for this. There are no plans for additional tooling adjustments.

Chart 1. ORNL Shield Cup Assembly Length from -A- (2.79/3.56 mm)

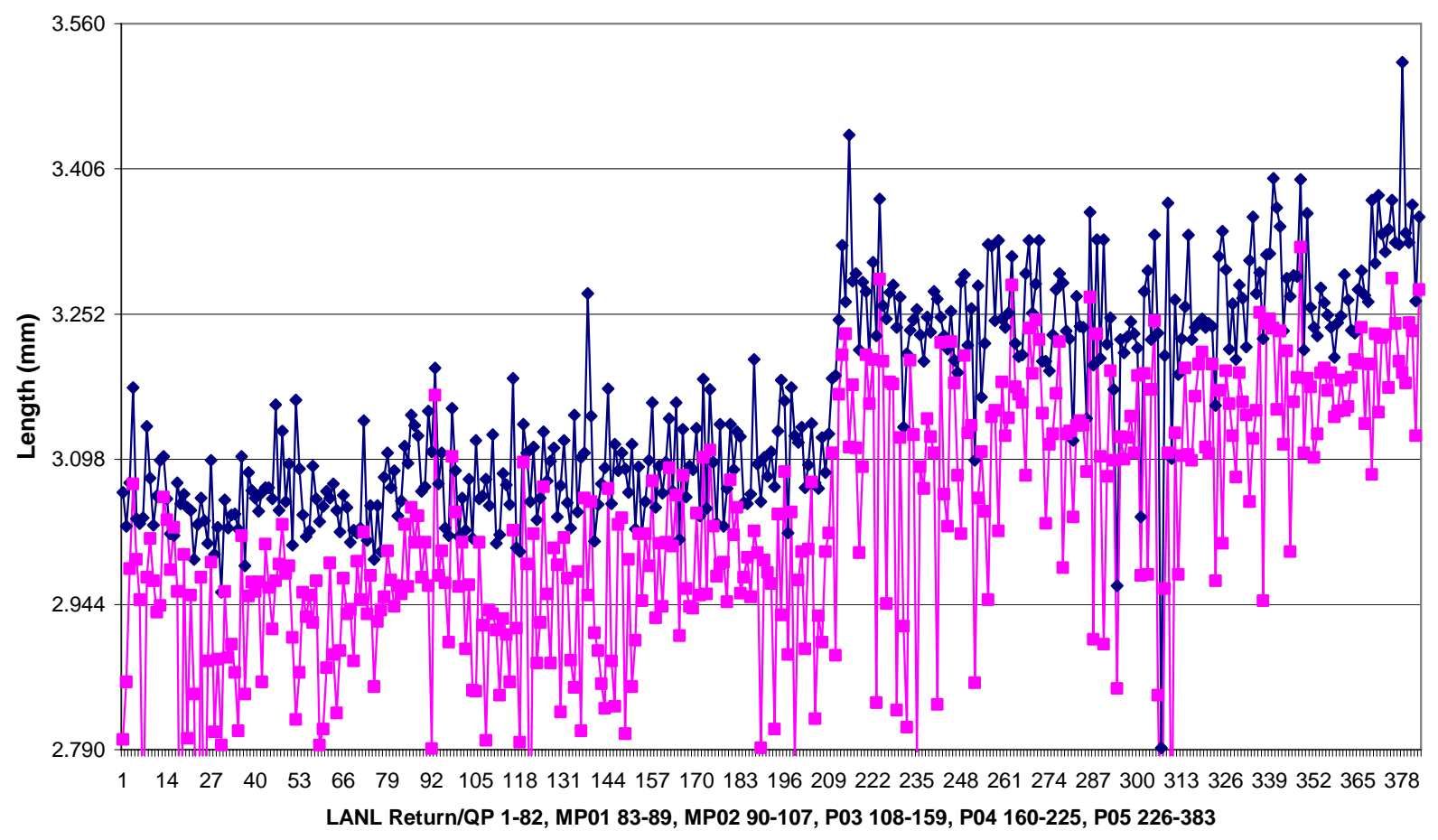

Length from -A- Max. $3.56-$ Length from -A- Min. 2.79

Table 5. Shield Cup Assembly/Weld Shield Length from -A- Values By Fixture (mm)

\begin{tabular}{l|cccccc}
\hline & \multicolumn{2}{|c}{ Fixture 1 } & \multicolumn{2}{c}{ Fixture 2 } & \multicolumn{2}{c}{ Fixture 3 } \\
\cline { 2 - 6 } & Max Length & Min Length & Max Length & Min Length & Max Length & Min Length \\
\hline Average & 3.267 & 3.079 & 3.264 & 3.153 & 3.261 & 3.151 \\
Std Dev & 0.064 & 0.126 & 0.079 & 0.076 & 0.053 & 0.084 \\
Min & 3.118 & 2.788 & 2.964 & 2.855 & 3.097 & 2.861 \\
Max & 3.442 & 3.289 & 3.519 & 3.290 & 3.395 & 3.323 \\
\hline
\end{tabular}

\subsubsection{High Temperature Vacuum Furnace Upgrades}

The original brass piping and valves for both Furnace A (graphite hot zone for frit vent sintering and diffusion bonding) and Furnace B (refractory metal hot zone for cup recrystallization and 
assembly vacuum outgassing) were replaced with easier-to-troubleshoot components that are stainless steel. The systems are working well.

\subsubsection{Tooling Maintenance/Evaluations}

The weld shield butt weld process was reviewed for data trends with regard to rewelds and burnback. Higher incidences of rewelds and burnback were found with fixtures 1-3 versus fixtures 4-6. Sixteen new clamps and 8 specimen holders made of nickel-plated copper are being fabricated. These will be evaluated in FY06.

Back-up tooling sets for frit vent backing and cover disc piercing are being fabricated. They will be evaluated in FY06.

Two back-up $2^{\text {nd }}$-form punches have been fabricated and inspected. They are stored for future production use.

Four new full sets of ATJ graphite sintering and diffusion bonding tooling were successfully fabricated at a cost of $\$ 3500$.

\subsubsection{Frit Vent Assembly Powder and Foil Evaluations}

Approximately 40g of prime frit vent assembly production powder remain from lot 91-0087-jar 4C. Efforts were begun in FY05 to qualify additional iridium powder for use as prime frit vent assembly production powder. Sample powders from five lots are being evaluated. This effort will continue in FY06.

In mid FY05 it was realized that increased, but within specification, foil thicknesses caused difficulties in frit vent assembly manufacturing. Chart 2 shows the slight upward trend in foil thicknesses since the end of Cassini production and the more pronounced upward trend in the most recent 46 foil pieces starting with GFR241. Table 6 shows the averages for foil thickness maximums and minimums during and after Cassini as well as for current foil (inspected in 2004 and used in 2005). The graphical trends in Chart 2 and the averages in Table 6 are consistent with each other.

During FY05 22 frit vent assemblies were scrapped along with 12 each frit vent backing and cover discs because foil thicknesses toward the upper limit of $0.16 \mathrm{~mm}$ are too thick for the current frit vent assembly powder and process. The frit vent assembly thickness limit is $0.41 \mathrm{~mm}$ maximum. When frit vent backing and cover disc thicknesses are near $0.15 / 0.16 \mathrm{~mm}$ too much compression of the frit vent assemblies is required to meet the thickness limit. If the thickness limit is met, then the frit vent assembly flow rates are reduced below the lower specification limit of $4.5 \mathrm{cc} / \mathrm{min}$. Note: foil thicknesses toward the $0.16 \mathrm{~mm}$ upper limit do not cause welding problems for the weld shield butt weld, the weld shield tab-to-cup weld, or the decontamination cover-to-cup weld based on welding of thicker foil parts to non-prime cups. It is planned that foil with thicknesses equal to or greater than $0.145 \mathrm{~mm}$ will not be used for frit vent backing and cover discs. 
Chart 2. Iridium Alloy Foil Thicknesses $(0.16 / 0.10 \mathrm{~mm})$

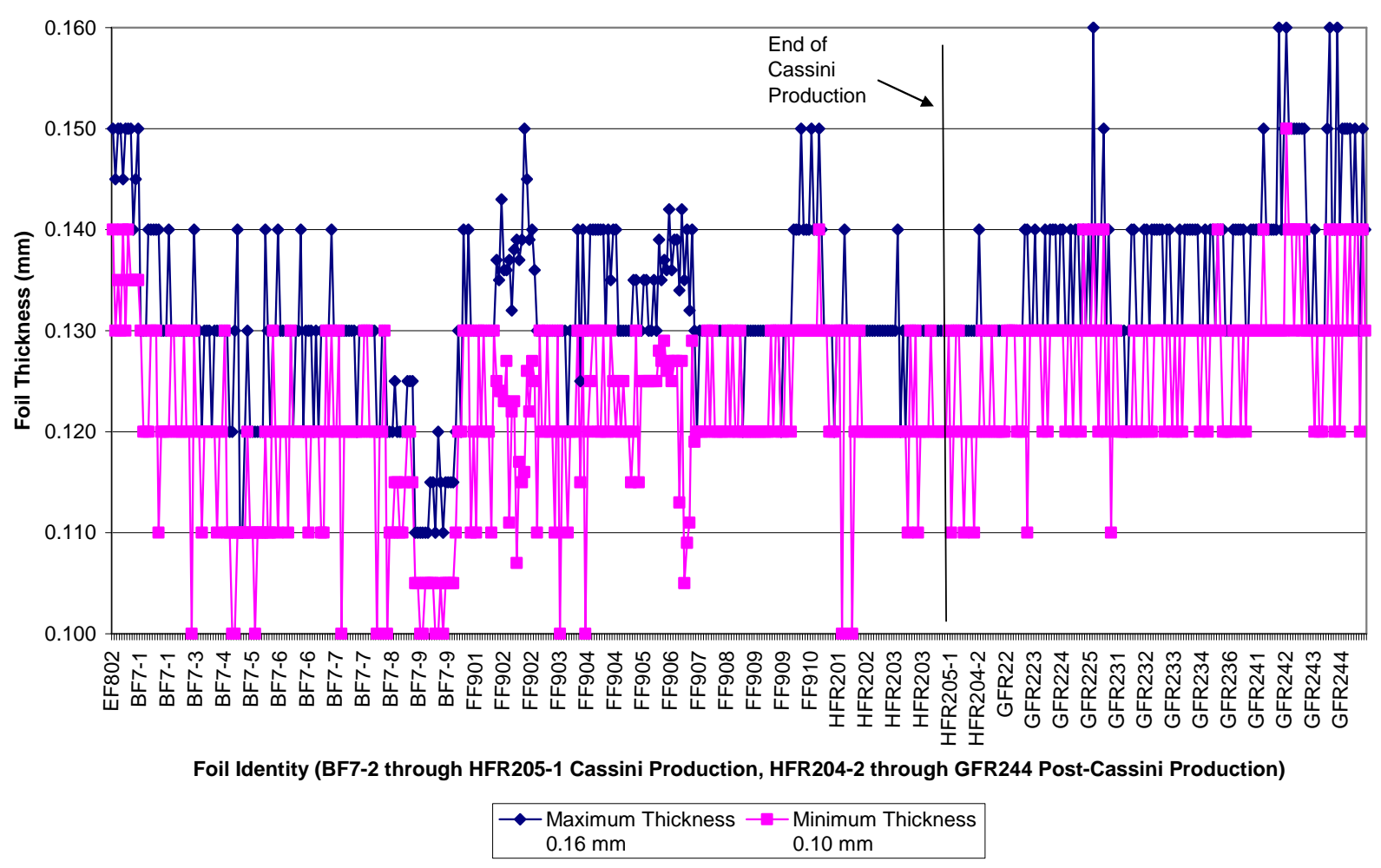

Table 6. Foil Thickness Averages (mm)

\begin{tabular}{l|ccc}
\hline Production Era (Inspection Dates) & Number of Foil Pieces & Maximum & Minimum \\
\hline Cassini $(9 / 90-8 / 94)$ & 311 & 0.130 & 0.120 \\
Post-Cassini (8/94 -8/04) & 160 & 0.137 & 0.127 \\
Current $(8 / 04)$ & 46 & 0.144 & 0.132 \\
\hline
\end{tabular}

\subsubsection{Cup Second-Form Die Evaluation}

Nine test cups ( 3 sets of 3 each) were $2^{\text {nd }}$-formed with three dies of different entrant radii and forming surface lengths using non-prime blanks. The same $2^{\text {nd }}$-form punch was used to form all 9 cups. The dies had the following entrant radius/forming surface length combinations (units in inches): 0.318/0.285 (cups TC142 - TC144), 0.090/0.288 (cups TC145 - TC147), and $0.360 / 0.410$ (cups TC148 - TC150). The current nominal drawing requirements (T2E-140186, Rev. F) are for an entrant radius of 0.30 " and a forming surface length of 0.38 ".

All 9 cups were formed and fabricated to finished cups. Cups TC145 - TC147 formed with the sharpest entrant radius $\left(0.090^{\prime \prime}\right)$ had rounded bottoms in the as-formed condition. These cups tended to have the thinnest weld zone wall thicknesses while cups TC148 - TC150 formed with the largest entrant radius $(0.360 ")$ and the longest forming surface $\left(0.410^{\prime \prime}\right)$ tended to have the thickest weld zone wall thicknesses. Cups TC142 - TC144 formed with an entrant radius of 0.318 " and a forming surface length of 0.285 " tended to have the most uniform as-formed and 
finished dimensions. An additional iteration using a $2^{\text {nd }}$-form die with an entrant radius of 0.150 " and a forming surface length of 0.200" will be evaluated as time permits in FY06.

\subsubsection{Deviation Request and Nonconformance Report Summaries}

Seven deviation requests (DR-CVS-052 through 058), involving eight procedures, were submitted and accepted during FY05. Seven nonconformance reports (NCR-CVS-062 through 068); involving one shield cup, one vent cup assembly, ten shield cup assemblies, and four matched assemblies, were submitted and accepted during FY05. All of these parts became engineering use units except for the shield cup which was rejected for being dropped and four of the shield cup assemblies maintained prime status.

\subsubsection{Production Summaries}

Table 7 is the part production summary for FY05. This shows the quantity of parts produced or processed from start to finish in FY05 (second column) along with the quantity of those parts that finished as prime (third column). The destructive test cups are not included in the vent and shield cup quantities because finished cups are not usually used for destructive test cups, therefore destructive test cups do not qualify as "produced" cups for Table 7. The fourth column shows the calculated percentage yield of prime parts from the quantity produced. It must be noted that the quantity produced includes all parts that were started - prime or engineering use. This means the prime yields for the vent cup assemblies, shield cup assemblies, and matched assemblies are not true process yields because if a part starts as engineering use it usually can never attain prime status. Removing these quantities of engineering use parts at the start of a process gives prime process yields of $99 \%$ for vent cup assemblies, $99 \%$ for shield cup assemblies, and $100 \%$ for matched assemblies.

Table 7. FY05 Part Production Summary

\begin{tabular}{l|ccc}
\hline Part Type Name and Number & Quantity Produced & Prime Quantity & Prime Yield - \% \\
\hline Decontamination Cover - 3619 & 56 & 56 & 100 \\
Weld Shield -3620 & 141 & 118 & 84 \\
Frit Vent Backing Disc - 3621 & 157 & 143 & 91 \\
Frit Vent Cover Disc - 3621 & 155 & 143 & 92 \\
Vent Cup - 3624 & 87 & 87 & 100 \\
Shield Cup - 3625 & 77 & 76 & 99 \\
Frit Vent Assembly -9752 & 147 & 120 & 82 \\
Vent Cup Assembly - 9753 & 149 & 142 & 95 \\
Shield Cup Assembly - 9754 & 153 & 143 & 93 \\
Matched Assembly - 9808 & 150 & 143 & 95 \\
\hline
\end{tabular}

Examination of the prime yields in Table 7 shows areas for process improvements in FY06. These will involve the weld shields, frit vent backing and cover discs, and the frit vent assemblies. Most of the weld shield losses were because of excessive burnback during the butt welding process. New tooling will be evaluated. The frit vent backing and cover disc losses were due to excessive foil thicknesses for the current frit vent assembly process. Frit vent backing and cover disc thicknesses will be restricted to 0.100 to $0.145 \mathrm{~mm}$. Also the majority of frit vent assembly losses was because of excessive frit vent backing and covers disc thicknesses. These thicknesses will be restricted and new powder will be evaluated for prime production use. 


\subsection{IRIDIUM POWDER AND INVENTORY MANAGEMENT}

The purpose of this work is to manage an iridium inventory for all heat source contractors with emphasis on the significant quantities of iridium located at Los Alamos National Laboratory and Oak Ridge National Laboratory and to maintain a no-change iridium inventory through an annual write-off of inventory and processing losses.

\subsubsection{Iridium Demand and Supply Schedule}

Table 8 is the demand and supply schedule, prepared for contingent planning purposes, presents a strategy to assess the availability of iridium for all RPS program activities by projecting future demands. An adequate inventory needs to be maintained to meet the needs of the MMRTG, Stirling Generator Program, and defense missions. The table indicates that enough iridium will be available for these missions.

The first part of Table 8 shows the estimated production demand factors for prime blanks and foil. The schedule of produced blanks and foil represents the quantity and timing for delivery or storage at ORNL. The ingots from new material represent the quantity produced from new iridium powder to make either blanks or foil. These ingots must be produced on a timely basis to meet the lead-time requirement to produce and deliver or store the blanks and foil.

The production of prime blanks and foil produces recyclable iridium material that can be placed back into the production process at ORNL. A greater economic benefit is realized by using recycled material, since the need to purchase powder from an outside vendor is reduced.

Refinable iridium scrap is also generated from the production of prime blanks, non-prime blanks, and foil. This scrap is sent to a commercial refinery when a sufficient accumulation occurs at ORNL, funding is available for the refining, and it makes economic sense based on a comparison of refining costs to that of new material.

Process losses of iridium occur during the working of the material at ORNL and Los Alamos National Laboratory. Losses also occur during the refining process. These inventory losses are written-off annually.

The information contained within the table can be summarized as follows. With the completion of the refining contracts in FY 2006, there will be an adequate supply of iridium powder to produce the hardware for MMRTG, Stirling Generator Program, and defense missions and $19 \mathrm{~kg}$ will remain at the beginning of FY 2009. 
Table 8. Demand and Supply Schedule Shows Factors and Provides Strategy to Ensure an Adequate Supply of Iridium Powder for MMRTG, Stirling Generator Program, and Defense Missions

\begin{tabular}{lllll}
\hline & \multicolumn{2}{l}{ U. S. Government fiscal years } & \\
\cline { 2 - 5 } Factors and strategy & FY 2005 & FY 2006 & FY 2007 & FY 2008 \\
\hline Production-demand factors & 284 & 60 & 180 & 240 \\
Produced blanks ${ }^{1}$ & 2 & 1 & 1 & 2 \\
Ingots from new material & 1 & 0 & 1 & 1 \\
Ingots from recyclable material & 0 & 0 & 0.4 & 0 \\
Produced foil (m $\left.{ }^{2}\right)$ & & & & \\
Refining and process losses $(\mathrm{kg})$ & 0 & 10.0 & 0 & 0 \\
Refining loss & 15.0 & 10.0 & 7.8 & 7.8 \\
Processing losses & & & & \\
Supply strategy (kg) & & & & \\
Beginning balance of powder & 82 & 48 & 70 & 53 \\
Receipt of refined powder & 0 & 42 & 0 & 0 \\
Receipt of purchased powder & 0 & 0 & 0 & 0 \\
\hline
\end{tabular}

${ }^{1}$ Estimate of maximum number of blanks

${ }^{2} \mathrm{FY} 2009$ beginning balance of powder is estimated to be $19 \mathrm{~kg}$.

\subsubsection{Annual Write-Off}

The annual fiscal year 2005 write-off of iridium inventory was completed in July. A total of 17.0 $\mathrm{kg}$ of iridium was written off as a normal operating loss. The write-off appropriately reduced the non-fund iridium inventory. This $17.0 \mathrm{~kg}$ loss was considered a normal operating loss compared to the history of iridium losses during the past several years.

\subsubsection{Iridium Accountability Reviews}

The review at ORNL was conducted in June. The purpose of this review was to evaluate the accountability, physical inventory, and security of iridium at ORNL. It was concluded that the accountability, physical inventory, and security for the iridium was in place and operating in a proper manner. No recommendations were necessary.

The review at LANL was conduced in July. The purpose of this review was to evaluate the accountability, physical inventory, and security of iridium at LANL. It was concluded that the accountability, physical inventory, and security for the iridium was in place and operating in a proper manner. No recommendations were necessary. 


\subsubsection{Shipment of Iridium}

The shipment of twenty-one (21) iridium alloy clad vent sets departed ORNL on December 6 and arrived at LANL on December 7. The security seals on the shipping container were intact upon arriving at LANL. U. S. Department of Energy Transfer Voucher No. 100-OR4-NS1-121 dated December 14 was issued to properly account for this shipment.

The shipment of six (6) stimulant fuel clads were shipped from LANL to Idaho National Laboratory in December. U. S. Department of Energy Transfer Voucher No. 503-NS1-CH2-002 dated December 21 was issued to properly account for this shipment.

The shipment of thirty-nine (39) iridium alloy clad vent sets departed ORNL on January 5 and arrived at LANL on January 6. The security seals on the shipping container were intact upon arriving at LANL. U. S. Department of Energy Transfer Voucher No. 100-OR4-NS1-122 dated February 3 was issued to properly account for this shipment.

The shipment of twenty-eight (28) iridium alloy clad vent sets departed ORNL on April 25 and arrived at LANL on April 26. The security seals on the shipping container were intact upon arriving at LANL. U. S. Department of Energy Transfer Voucher No. 100-OR4-NS1-123 dated May 12 was issued to properly account for this shipment.

The shipment of sixteen (16) iridium alloy clad vent sets departed ORNL on June 20 and arrived at LANL on June 21. The security seals on the shipping container were intact upon arriving at LANL. U. S. Department of Energy Transfer Voucher No. 100-OR4-NS1-124 dated June 21 was issued to properly account for this shipment.

The shipment of forty-two (42) iridium alloy clad vent sets departed ORNL on August 30 and arrived at LANL on August 31. The security seals on the shipping container were intact upon arriving at LANL. U. S. Department of Energy Transfer Voucher No. 100-OR4-NS1-125 dated September 5 was issued to properly account for this shipment.

\section{Other Iridium Locations}

In March an effort was initiated to determine the outcome of the 3,273 grams of iridium listed as others on the Subtask 2.D. Iridium Inventory Management table showing the amount of iridium at each site on the Monthly Technical, Financial, and Schedule Status Report at the Oak Ridge National Laboratory for the Office of Space and Defense Power Systems. The outcome of that effort is detailed below:

It was determined that the 12 grams of iridium located at the University of Cincinnati, the 57 grams located at Michigan Tech University, the 44 grams located at North Carolina State University, and the 112 grams located at the University of Pennsylvania had been consumed in experimentation at these universities. These losses were written off the RPS iridium inventory in the annual fiscal year 2005 write-off of iridium inventory completed in July.

Of the total 155 grams located at Dartmouth College, 127 grams was returned to ORNL and the remaining 28 grams was consumed in experimentation. This loss of 28 grams was written off the RPS iridium inventory in the annual fiscal year 2005 write-off of iridium inventory completed in July. 
Of the total 600 grams located at Ames Laboratory, 303 grams was returned to ORNL and the remaining 297 grams was consumed in experimentation. This loss of 297 grams was written off the RPS iridium inventory in the annual fiscal year 2005 write-off of iridium inventory completed in July.

Of the total 318 grams located at Lockheed Martin Space Power, 213 grams remain at Lockheed Martin Space Power and the remaining 105 grams was consumed in the processing of parts fabricated during the Cassini mission. This loss of 105 grams was written off the RPS iridium inventory in the annual fiscal year 2005 write-off of iridium inventory completed in July. 


\section{ALLOY CHARACTERIZATION}

\subsection{TENSILE BEHAVIOR OF Ta-10W}

\subsubsection{Introduction}

The objective of this task is to characterize the mechanical and metallurgical properties of metallic materials that are of interest to the Radioisotope Power Systems Program. Current materials of interest include DOP-26 iridium, Haynes 25, and Ta-10W. Summarized below are the results of our activities during FY 2005.

\subsubsection{Effect of Grain Size on the Low-Temperature Tensile Impact Ductility of DOP-26 Iridium}

DOP-26 iridium has been used successfully as a fuel-cladding material in radioisotope thermoelectric generators (RTGs) aboard many interplanetary spacecraft. New RTGs being considered for future NASA missions have lower operating temperatures than previous designs. To support these new missions, studies were initiated a couple of years ago to generate lowtemperature impact data. In FY 2004 we measured [1] the impact ductilities of DOP-26 iridium in the as-recrystallized condition $\left(1375^{\circ} \mathrm{C} / 1 \mathrm{~h}\right)$ at temperatures of $500-900^{\circ} \mathrm{C}$. The grain size of this material was $23 \mu \mathrm{m}$. In FY 2005 we expanded the investigation [2] to larger grain sizes, up to $\sim 35 \mu \mathrm{m}$. For all the grain sizes investigated, ductility was found to increase with increasing test temperature. Associated with this increase in ductility is a change in the fracture mode from intergranular to transgranular. Additional tests are planned in FY 2006 for the 30 and $35 \mu \mathrm{m}$ grain sizes to duplicate the test matrix previously completed for the $23 \mu \mathrm{m}$ grain size ( 4 specimens at each grain size and test temperature). This will enable us to determine the range of grain sizes and test temperatures for which a given minimum level of ductility can be obtained.

\subsubsection{Mechanical Properties of Haynes Alloy 25}

Haynes alloy 25 is used as a structural material in many important high-temperature applications. However, much of the currently available mechanical properties data on Haynes 25 were generated several decades ago. Because of that it was judged prudent to re-evaluate the properties of Haynes 25 using specimens from a more recent heat rather than relying only on historical data. We measured tensile properties at intermediate temperatures as a function of test temperature, strain rate, grain size, and environment [3]. In addition, the effects of long-term aging at 550, 675, and $850^{\circ} \mathrm{C}$ were investigated [3]. An intermediate-temperature ductility loss occurs at temperatures of approximately 600 to $800^{\circ} \mathrm{C}$, with the minimum occurring at approximately $750^{\circ} \mathrm{C}$. Ductility increases with increasing strain rate, suggesting a possible connection to environment, but no difference was observed in air, vacuum, and oxygen, suggesting that oxygen is probably not the culprit.

The effect of aging at temperatures of $550-850^{\circ} \mathrm{C}$ was also studied. Aging at $550^{\circ} \mathrm{C}$ for times up to $10,000 \mathrm{~h}$ did not appear to affect the tensile strength or ductility of specimens tested at $750^{\circ} \mathrm{C}$. Aging for times up to $210 \mathrm{~h}$ at $850^{\circ} \mathrm{C}$ resulted in strengths and elongations comparable to those of specimens aged at $550^{\circ} \mathrm{C}$, but longer aging times resulted in reduced ductilities consistent with the formation and growth of Co-W-containing precipitates. At much longer aging times, 10,000$24,570 \mathrm{~h}$, slightly increased strength and ductility values were noted. Specimens aged at $675^{\circ} \mathrm{C}$ were tensile tested at $650^{\circ} \mathrm{C}$ and showed a decrease in ductility for aging times longer than $\sim 200$ $h$. In each of these cases, the embrittlement was associated with grain-boundary fracture. 
High-strain-rate tensile impact ductilities were determined for as-received Haynes 25 as a function of impact temperature, and at $675^{\circ} \mathrm{C}$ as a function of aging temperature. The as-received material exhibited high elongations (56-74\%) and a ductile failure mode at temperatures of 600$1000^{\circ} \mathrm{C}$. Similarly high ductilities were observed after aging for times up to $10,000 \mathrm{~h}$ at $550^{\circ} \mathrm{C}$ even though the TTT diagram shows the formation of $\mathrm{Co}-\mathrm{W}$ precipitates under these conditions. A possible explanation for this behavior is that the Co-W intermetallics form mainly within the grains, where they are relatively benign, and not on the grain boundaries, where they can cause embrittlement. High ductilities were also obtained in specimens aged for times to $168 \mathrm{~h}$ at $675^{\circ} \mathrm{C}$ and $10 \mathrm{~h}$ at $850^{\circ} \mathrm{C}$. However, longer aging times at these temperatures resulted in reduced ductilities and brittle intergranular fracture, consistent with the $\mathrm{Co}-\mathrm{W}$ intermetallics predicted by the TTT diagram.

To investigate the effects of grain size and strain rate on aging embrittlement of Haynes 25, specimens with grain sizes of 75,288 , and $476 \mu \mathrm{m}$ were aged at temperatures of 550 and $850^{\circ} \mathrm{C}$ for times up to $10,000 \mathrm{~h}$. Conventional tensile tests were conducted in vacuum at $750^{\circ} \mathrm{C}$ and a strain rate of $10^{-3} \mathrm{~s}^{-1}$. As expected, strength decreased with increasing grain size. Ductility, on the other hand, was more or less independent of grain size. Impact tests, conducted at $675^{\circ} \mathrm{C}$ and a strain rate of $10^{3} \mathrm{~s}^{-1}$, also showed no dependence on grain size, with ductilities similar to those obtained in conventional tensile tests.

\subsubsection{Compatibility of Haynes Alloy 25 with Graphite}

The purpose of this study [4] was to evaluate the compatibility of Haynes 25 with graphite by performing long-term aging studies in the presence and absence of graphite. Three sets of aging experiments were conducted at $675^{\circ} \mathrm{C}$ for times up to $20,000 \mathrm{~h}$. In some of the experiments the Haynes 25 was in intimate physical contact with the graphite whereas in others a small gap was maintained between the two materials during the aging treatment. Vickers microhardness and conventional tensile testing were used to evaluate mechanical properties as a function of aging. Optical metallography, scanning electron microscopy, and energy dispersive spectroscopy were used to analyze microstructural changes and to determine whether any carbides had formed after aging. The results showed no evidence for the formation of carbides by the diffusion of carbon into the Haynes 25 material, either through the bulk or along grain boundaries originating at the Haynes 25-graphite interface. The mechanical properties of Haynes alloy 25 (strength, ductility, and hardness) were the same regardless of whether the aging was performed in the presence or absence of graphite.

\subsubsection{Effects of Oxygen on the Impact Ductility of Ta-10W}

Ta-10W is being considered as a pressure vessel material to contain the He gas that is released when the plutonia pellets decay during service. One of the potential problems associated with such an application is oxygen-induced embrittlement of Ta- $10 \mathrm{~W}$ from long-term exposure to the plutonia fuel. Oxygen is known to severely embrittle T-111, but little is known about its effects on Ta-10W. Another concern is whether Ta-10W will absorb more interstitial elements (especially oxygen) during processing than T-111 (because of the lack of Hf). In FY 2004 we investigated [5] the effects of oxygen on the mechanical properties of Ta-10 $\mathrm{W}$ at conventional strain rates $\left(\sim 10^{-3} \mathrm{~s}^{-1}\right)$. During FY 2005, we initiated a study of oxygen effects on impact ductility [6]. In general, ductility decreased with increasing oxygen concentration. Associated with this drop in ductility was a change in the fracture mode from ductile transgranular to brittle intergranular. The oxygen concentration at which ductility decreases sharply (the ductile-brittle transition) depends on the test temperature. For the temperatures investigated so far (up to 
$500^{\circ} \mathrm{C}$ ), the ductile-brittle transition appears to shift to higher oxygen concentrations as the impact test temperature is increased. This is an ongoing study and in the next fiscal year we will perform impact tests at higher temperatures, up to $1100^{\circ} \mathrm{C}$.

\subsubsection{Effect of Copper on the Impact Ductility of DOP-26 Iridium at $980^{\circ} \mathrm{C}$}

During the past several years, we have investigated the effects of various trace elements and impurities on the metallurgical properties and mechanical behavior of DOP-26 iridium. These include $\mathrm{Th}$ and $\mathrm{Ce}$, which are beneficial; $\mathrm{Ni}, \mathrm{Fe}, \mathrm{Cr}$, and $\mathrm{Al}$, which are benign; and $\mathrm{Si}$, which is harmful. Recently, we began an investigation [7] of the effects of $\mathrm{Cu}$ because, during melting and casting, the DOP-26 alloy comes into contact with copper. Therefore, it is of interest to determine whether accidental contamination with $\mathrm{Cu}$ can have any deleterious effects. In FY 2005 our focus was on the effects of $\mathrm{Cu}$ on impact ductility. We chose as our starting point a heat treatment consisting of $19 \mathrm{~h}$ at $1500^{\circ} \mathrm{C}$ followed by tensile impact testing at $980^{\circ} \mathrm{C}$. These are the same conditions as those used for qualification of iridium powder during blank and foil production. In subsequent studies we plan to systematically investigate other variables, including grain size and test temperature, to better understand the underlying physical mechanisms. The effects of $\mathrm{Cu}$ concentrations in the range 24-42 ppm on the tensile impact ductility of DOP-26 iridium were investigated. Our preliminary results indicate an embrittling effect of $\mathrm{Cu}$ even at these low levels. The $\mathrm{Cu}$-containing alloys had both lower ductilities and greater amounts of intergranular fracture compared to DOP-26 alloys containing no added copper. Additional tests are planned to verify these preliminary results and identify the underlying physical mechanisms.

\subsubsection{References}

1. E. P. George, H. Bei, E. H. Lee, and J. D. Braden, Tensile Impact Ductility and Fracture Behavior of DOP-26 Iridium at $500-900^{\circ} \mathrm{C}$, Letter Report submitted to DOE-HQ, October 2004.

2. E. P. George, H. Bei, and J. D. Braden, Effect of Grain Size on the Tensile Impact Ductility of DOP-26 Iridium at 500-900 ${ }^{\circ}$, Letter Report submitted to DOE-HQ, October 2005.

3. C. G. McKamey and E. P. George, Mechanical Properties of Haynes Alloy 25 Before and After Aging at 550-850 ${ }^{\circ}$, Attachment to letter, J. F. King to John Dowicki, July 8, 2005.

4. C. G. McKamey and E. P. George, Compatibility of Haynes Alloy 25 with Graphite, Attachment to letter no. 0831-21-05, J. F. King to John Dowicki, Aug. 30, 2005.

5. E. P. George, H. Bei, and J. R. Distefano, Effects of Oxygen on the Tensile Properties of Ta$10 \mathrm{~W}$, Letter report submitted to DOE-HQ, Oct 2004.

6. E. P. George, H. Bei, J. D. Braden, and J. R. Distefano, Interim Report on the Effects of Oxygen on the Impact Ductility of Ta-10W, Letter report submitted to DOE-HQ, October 2005 .

7. E. P. George, H. Bei, J. D. Braden, and E. K. Ohriner, Effects of Copper on the Impact Ductility of DOP-26 Iridium at $980^{\circ} \mathrm{C}$, Letter report submitted to DOE-HQ, October 2005. 


\subsection{ORNL CHARACTERIZATION OF MIN-K TE-1400}

\subsubsection{Introduction}

Oak Ridge National Laboratory (ORNL) was requested to characterize the thermomechanical properties of Thermal Ceramics Min-K 1400TE material, hereafter referred to as Min-K, in support of its Multi-Mission Radioisotope Thermoelectric Generator (MMRTG) Program. In particular, ORNL was tasked with the determination of the high temperature compressive strength and stress relaxation behavior of Min-K up to $900^{\circ} \mathrm{C}$ in helium along with the formulation of a general model for the mechanical behavior exhibited by Min-K. Testing was to consist of general high temperature compressive mechanical testing, isothermal stress relaxation testing, and stress relaxation testing of samples exposed to a thermal gradient.

The tasks defined in the original scope of work consisted of the following.

\section{Task 1. Evaluation of Min-K material in compression as a function of temperature}

This included an assessment of size and geometric effect on the distribution of compressive strength of Min-K, determination of distribution of compressive strength of Min-K as a function of temperature, and statistical analysis of monotonic compressive strength results.

\section{Task 2. Stress Relaxation}

This involved determination of stress relaxation behavior under both isothermal and gradient temperature conditions.

\section{Task 3. Modeling}

This entailed the development of a simple unidirectional model to predict the stress-relaxation behavior of Min-K components when subjected to a constant strain under a temperature gradient.

\subsubsection{Experimental Procedures}

Initial compression testing was performed at room temperature at various loading rates ranging between 5 and $500 \mathrm{psi} /$ hour to determine the effect of sample size and geometry on the compressive strength of Min-K. Testing was performed using the set-up shown in Figure 1, which consists of an electromechanical testing machine (MTS Model 808) equipped with digital load and displacement controllers, computerized data acquisition, an alignment fixture, a $10 \mathrm{kN}$ load cell, and a single zone furnace. A plexiglass/aluminum environmental chamber with helium flow is used for controlling the environment. Testing was performed on three sample geometries shown in Figure 2. 


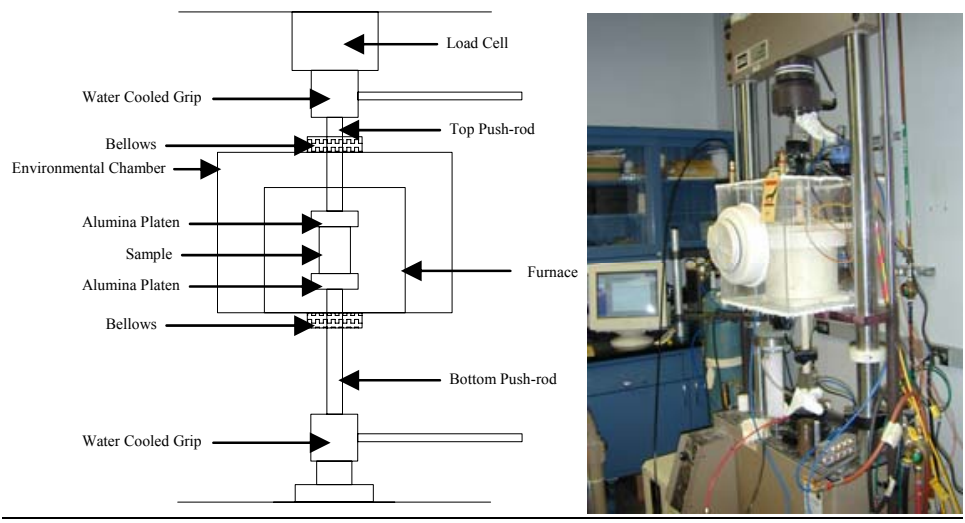

Figure 1. Experimental set-up for determination of compressive strength of Min-K

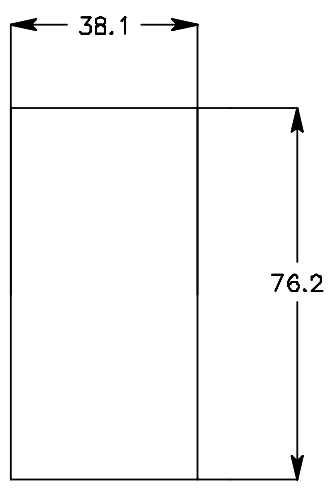

(a)

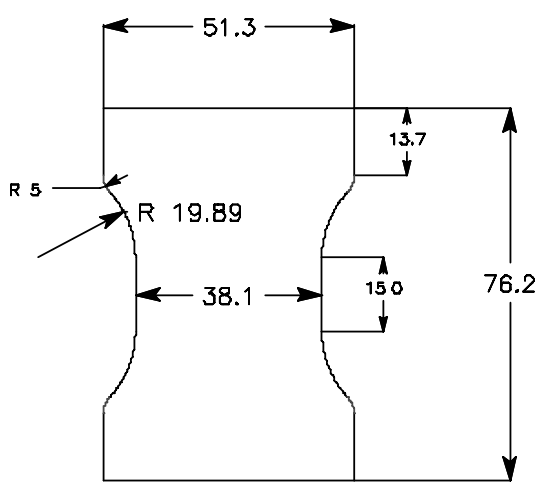

(b)

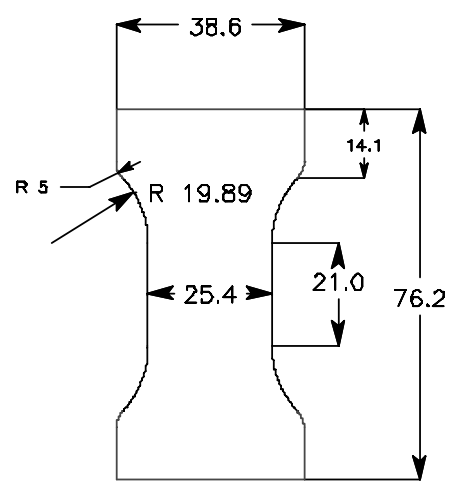

(c)

Figure 2. Sample Geometries for Initial Compression Testing (mm)

The results from these initial tests indicated that there was no effect of sample geometry on the monotonic compressive strength of Min-K. Therefore, subsequent testing was performed on cylindrical specimens (Figure 2.a). To determine the loading rates that would be used for stress relaxation tests, compression tests were carried out using the experimental set-up depicted in Figure 1. Testing was performed at various load rates under load or strain control utilizing constant and step loading functions (designated fast loading (200 psi $/ \mathrm{min}$ ), nominal loading $(5.56 \%$ strain/hour), and step loading (5.56\% strain/hour)). Sample loading was followed by stress relaxation under strain control. Examples of testing are shown in Figure 3. Test temperatures were 900,850 , and $650^{\circ} \mathrm{C}$. 


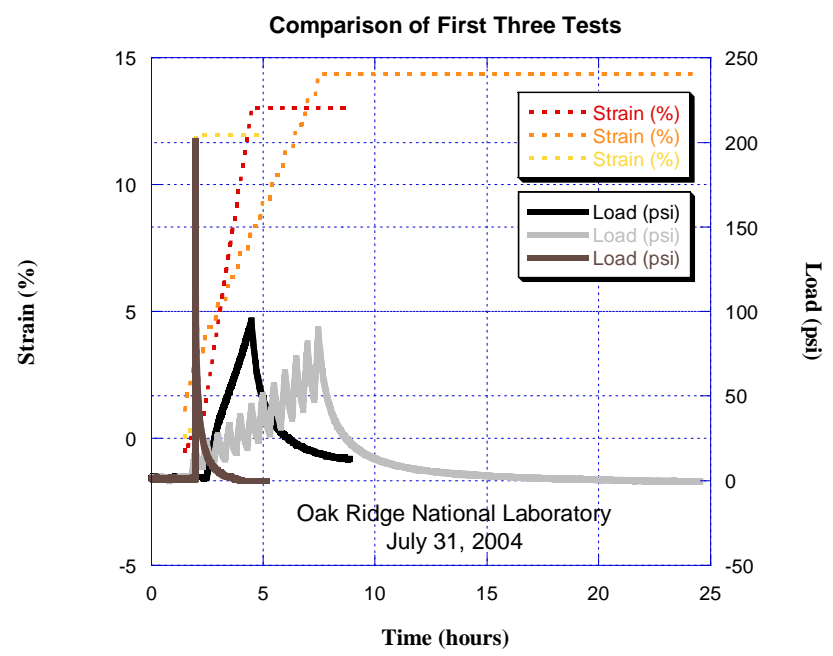

Figure 3. Loading and Relaxation Schemes for Preliminary High Temperature Compression Testing

Isothermal stress relaxation testing was performed at various temperatures and loads as indicated in Table 1 (Soaked Sequence) using 6" diameter, 2" long cylindrical samples. Testing was performed using the set-up shown in Figure 4, which consists of an electromechanical testing machine (Instron Model 1380) equipped with load and displacement analog controllers, an external LVDT for feedback displacement control, a $35 \mathrm{kN}$ load cell, and a single zone furnace. An aluminum environmental chamber with helium flow is used for controlling the environment. Loading was performed in strain control utilizing a 12 step loading scheme with loading every half hour at a rate of $5.56 \%$ strain/hour. Loading was followed by stress relaxation in strain control with testing carried out until the initial load was dissipated or has leveled off to an asymptotic value.

Table 1. Stress Relaxation Test Matrix

\begin{tabular}{|c|c|c|c|c|}
\hline \multicolumn{3}{|c}{ Temp Profile @ 50psi } & \multicolumn{2}{c|}{ Temp Profile @ 200psi } \\
\hline Temp C & $\begin{array}{c}\text { Gradient } \\
\text { Sequence }\end{array}$ & $\begin{array}{c}\text { Soaked } \\
\text { Sequence }\end{array}$ & $\begin{array}{c}\text { Gradient } \\
\text { Sequence }\end{array}$ & $\begin{array}{c}\text { Soaked } \\
\text { Sequence }\end{array}$ \\
\hline 190 & $4(450 * / 190 C)$ & 12,16 & $2(450 * / 190)$ & 10,15 \\
\hline 382 & - & 11,14 & - & 9,13 \\
\hline 813 & - & 7,8 & - & 5,6 \\
\hline 850 & $3(850 / 450 *)$ & 3,4 & $1(850 / 450 *)$ & 1,2 \\
\hline
\end{tabular}




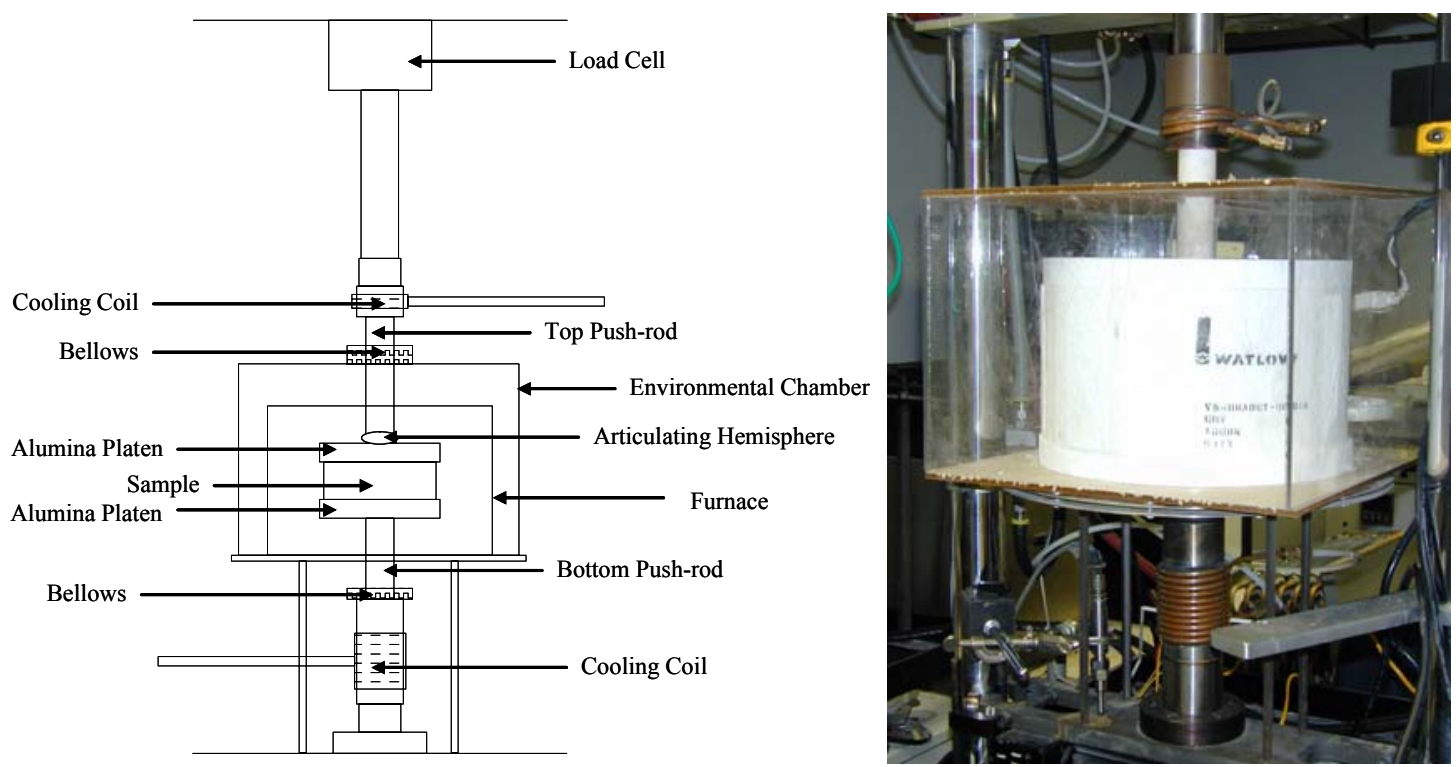

Figure 4. Isothermal Stress Relaxation Test Frame

Gradient stress relaxation testing was performed at various temperatures and loads as indicated in Table 1 (Gradient Sequence) using 6" diameter, 3" long cylindrical samples. Testing was performed using the set-up shown in Figure 5, which consists of an electromechanical testing machine (Instron Model 1380) equipped with load and displacement digital controllers, a $35 \mathrm{kN}$ load cell, a heated Inconel platen above the sample, and a single zone furnace. An aluminum environmental chamber with helium flow is used for controlling the environment. Loading was performed in strain control utilizing a 12 step loading scheme with loading every half hour at a rate of $5.56 \%$ strain/hour. Loading was followed by stress relaxation in strain control with testing carried out until the initial load is dissipated or has leveled off to an asymptotic value (up to 2000 hours).
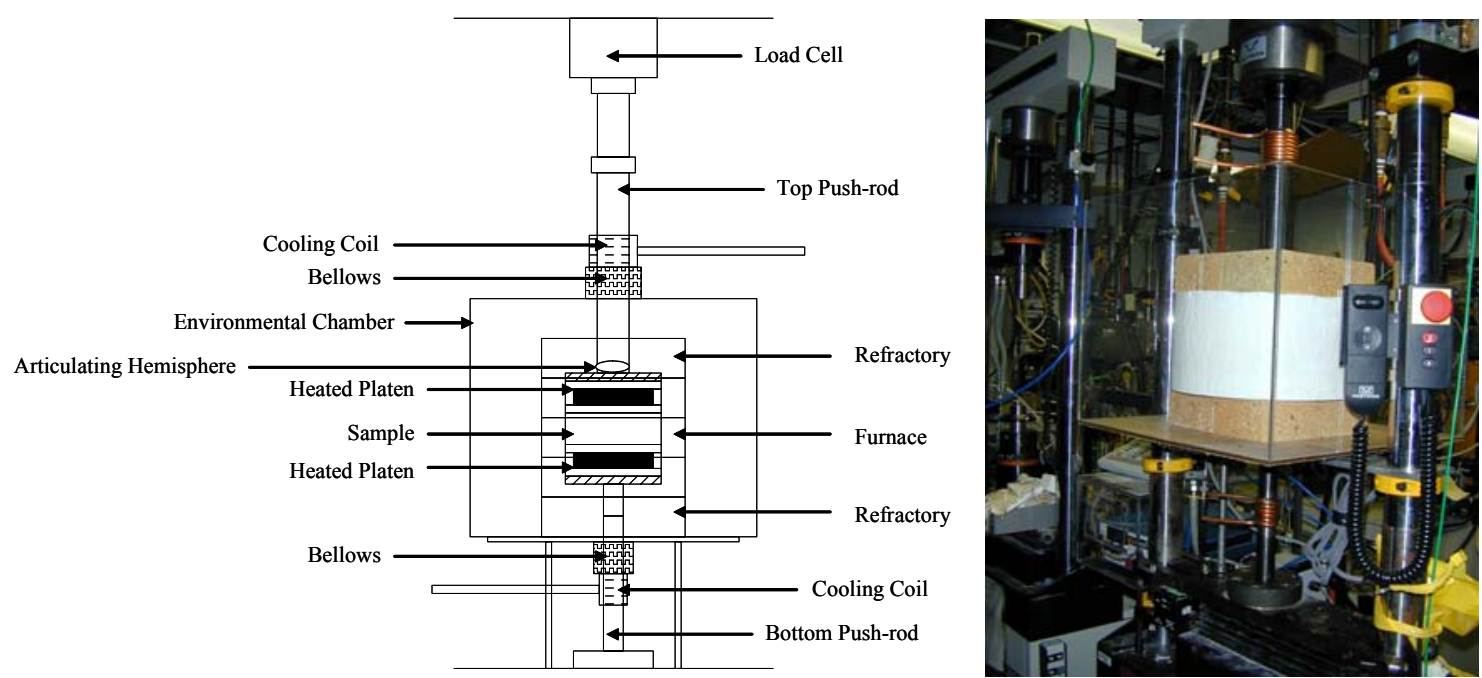

Figure 5. Gradient Stress Relaxation Test Frame 
High temperature compression testing was performed on cylindrical specimens (2" diameter, 3" length) using the experimental set-up depicted in Figure 1. Samples were loaded in load control at a rate of $53 \mathrm{psi} /$ hour in three load steps of 50, 100 and 200 psi with quick unload/load cycles between steps. Loading was followed by a hold period in load control (3 to 100 hours) to allow for sample creep. Testing was carried out at $850,813,382$, and $190^{\circ} \mathrm{C}$.

Experimental testing of Min-K under isothermal stress relaxation conditions has been completed at $850,813,382$, and $190^{\circ} \mathrm{C}$ with maximum initial stresses of 100 and 200 psi. The duration of these tests spans between 24 and 400 hours. This completed the original test matrix. Gradient stress relaxation testing was completed, although under slightly different thermal conditions then the originally proposed $850 / 450^{\circ} \mathrm{C}$ and $450 / 190^{\circ} \mathrm{C}$ with a maximum initial stress of 100 and 200 psi. The duration of these tests spans between 100 and 1300 hours. The temperatures of the isothermal stress relaxation tests were selected under the assumption that the creep deformation of Min-K, and consequently, its stress-relaxation behavior up to $850^{\circ} \mathrm{C}$ is a thermally-activated process with a well-defined activation energy. The temperatures for the gradient stress relaxation tests were selected to cover the entire temperature range explored in the isothermal testing. Actual test temperatures were dictated by the capabilities of the test system.

After completion of the original isothermal stress relaxation matrix, additional testing was requested. A temperature creep sweep test was performed on cylindrical specimens (2" diameter, 3 " length) using the experimental set-up depicted in Figure 1. This testing was undertaken to identify a suspected change in material behavior between the upper test temperatures (850 and $\left.813^{\circ} \mathrm{C}\right)$ and the lower test temperatures $\left(382\right.$ and $\left.190^{\circ} \mathrm{C}\right)$. Following completion of the temperature creep sweep test, isothermal stress relaxation testing was requested at 550 and $650^{\circ} \mathrm{C}$ with maximum stresses of 100 and 200 psi.

The applicability of the following model to describe the isothermal stress-relaxation of Min-K was investigated:

$$
\frac{\sigma}{\sigma_{0}}=\sum_{i=1}^{n} a_{i} e^{-\frac{t}{t_{i}}}
$$

In this model, $\sigma$ is the instantaneous stress at time $t, \sigma_{o}$ is the initial stress at the onset of stress relaxation (at the end of mechanical loading), $a_{i}$ is a temperature-dependent constant and $t_{i}$ constitutes a spectrum of relaxation times. It will be assumed that the spectrum of relaxation times is logarithmically-distributed and that the temperature dependence of $a_{i}$ is described according to an Arrhenius relationship.

To analyze the stress-relaxation behavior of a Min-K component subjected to a constant axial strain under a temperature gradient, the component will be discretized in isothermal sections and the stress-relaxation of each section will be described using Equation 1 as shown in Figure 6. 


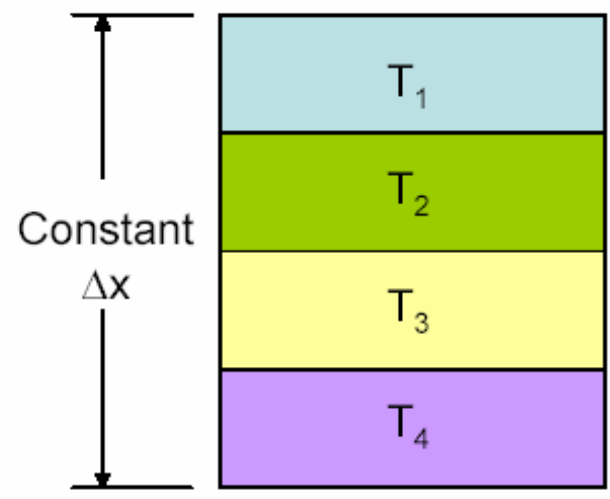

Figure 6. Disceretized Gradient Model

The concept of developing a closed-form solution was also investigated, along with using finiteelement methods to describe the stress-relaxation of the Min-K component.

\subsubsection{Results}

Results from initial compression testing of various sample sizes and geometries are shown in Appendix 1. The key finding from this testing was that the simple cylindrical samples presented the most logical sample geometry due to the ease of sample fabrication and the simplified data analysis as compared to the hour glass sample geometries. Additionally, the data obtained using the cylindrical geometry samples was comparable to that obtained with the two hour glass geometries after correction for effects of these geometries was made (i.e. correction for neck portions of samples and non-uniform cross section of samples). This is shown in Figure 7.
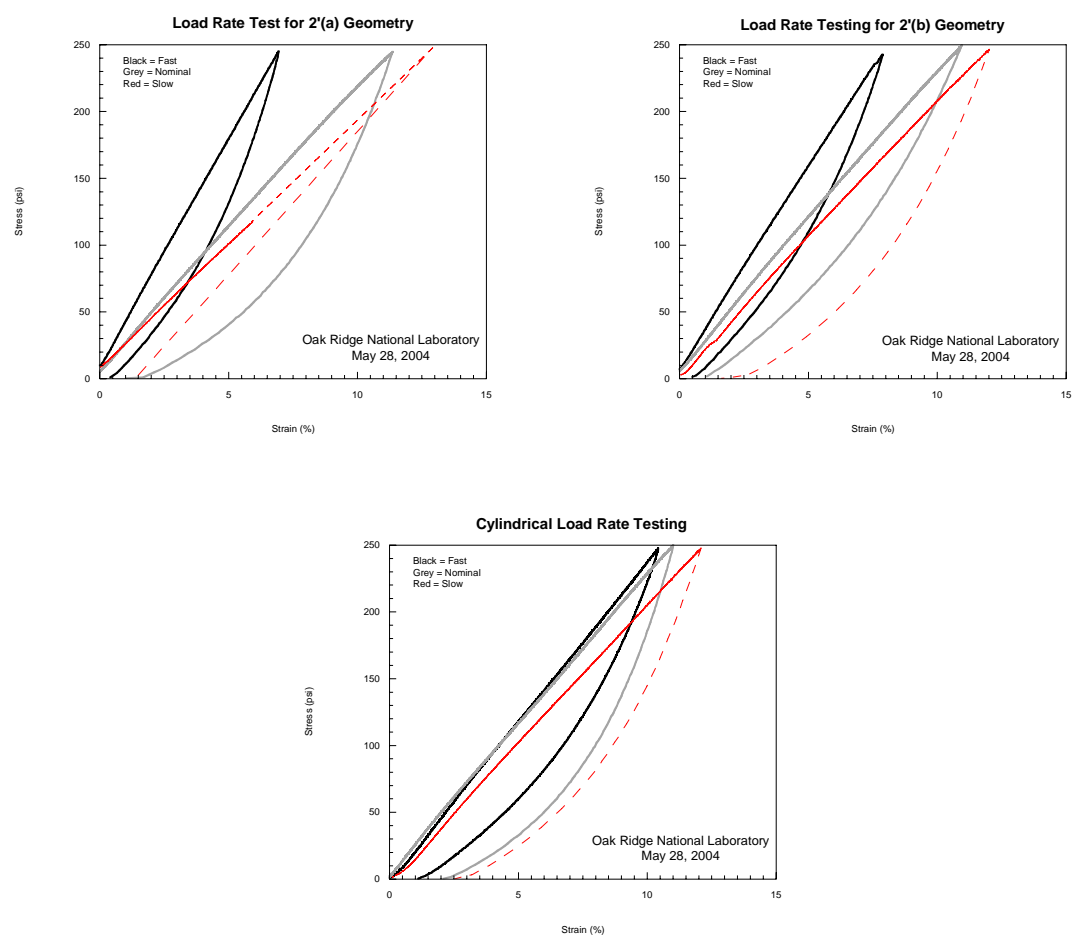

Figure 7. Results of Initial Compression Testing 
Results from preliminary high temperature compression testing are shown in Figure 8. The key results from this testing were the determination of loading schemes for subsequent stress relaxation testing and high temperature compression testing. It was determined that stress relaxation samples would be loaded in strain control utilizing a 12 step loading scheme with loading every half hour at a rate of $5.56 \%$ strain/hour. High temperature compression samples will be loaded in load control at a rate of $53 \mathrm{psi} /$ hour followed by a designated hold in load control of 3 to 100 hours to allow for sample creep.

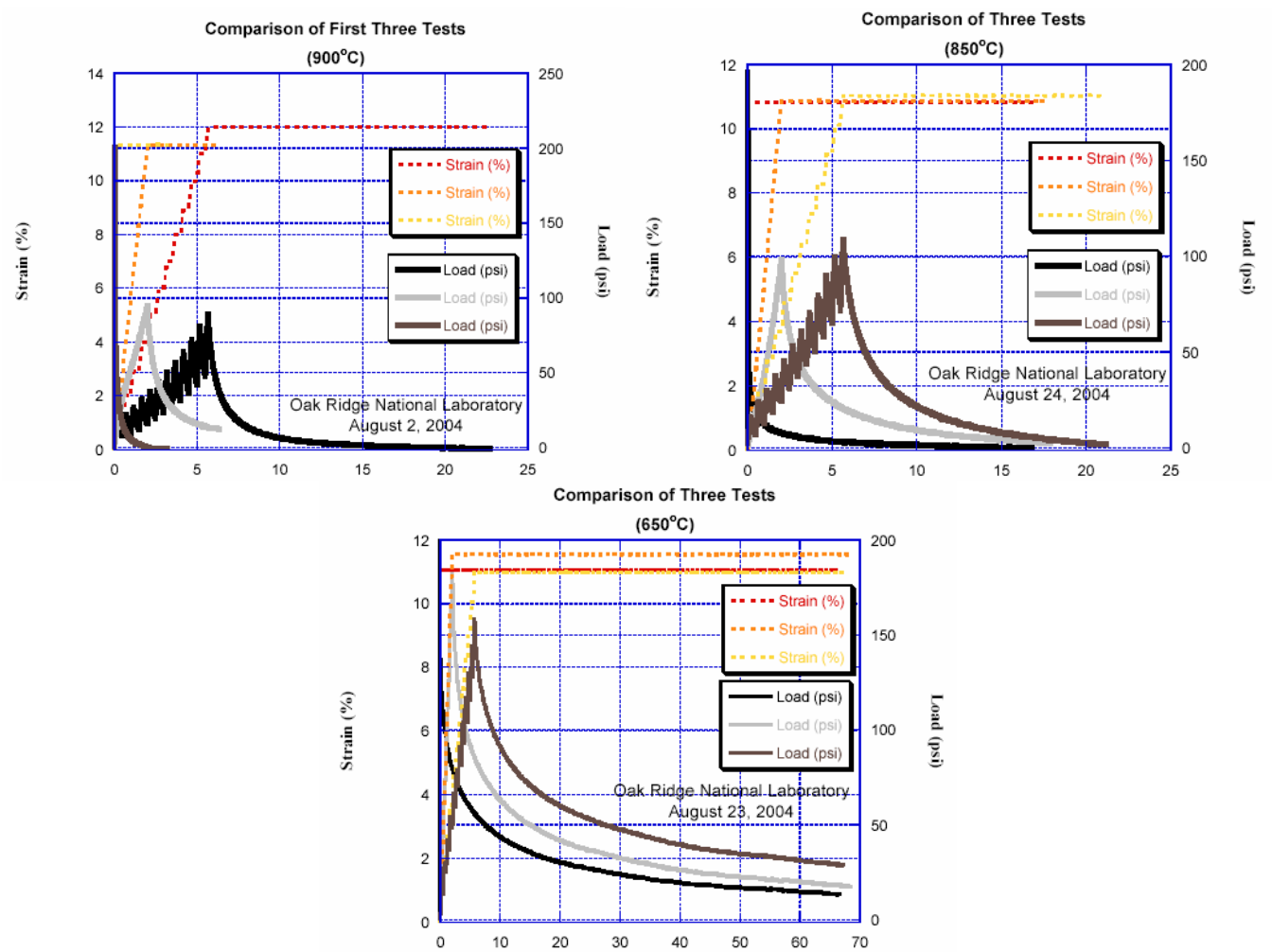

Figure 8. Results from Preliminary High Temperature Compression Testing

Typical results from isothermal and gradient stress relaxation testing are shown in Figure 9 and Figure 10 , respectively. Initial isothermal testing was completed at $850,813,382$, and $190^{\circ} \mathrm{C}$ and initial stresses of 100 and 200 psi. Additional isothermal testing has been completed at 650 and $550^{\circ} \mathrm{C}$ and initial stress of $200 \mathrm{psi}$. Gradient testing has been carried out over temperature gradients of $850 / 275^{\circ} \mathrm{C}$ and $400 / 190^{\circ} \mathrm{C}$, with initial stresses of 100 and 200 psi. 

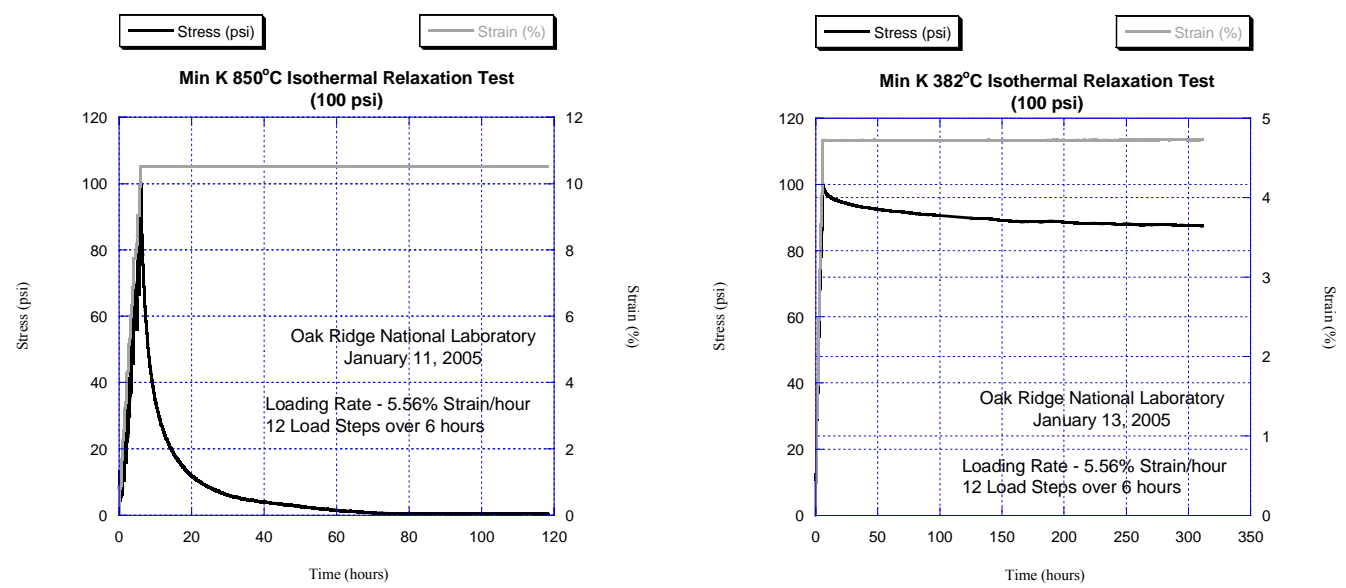

Figure 9. Typical Results from Isothermal Stress Relaxation Testing

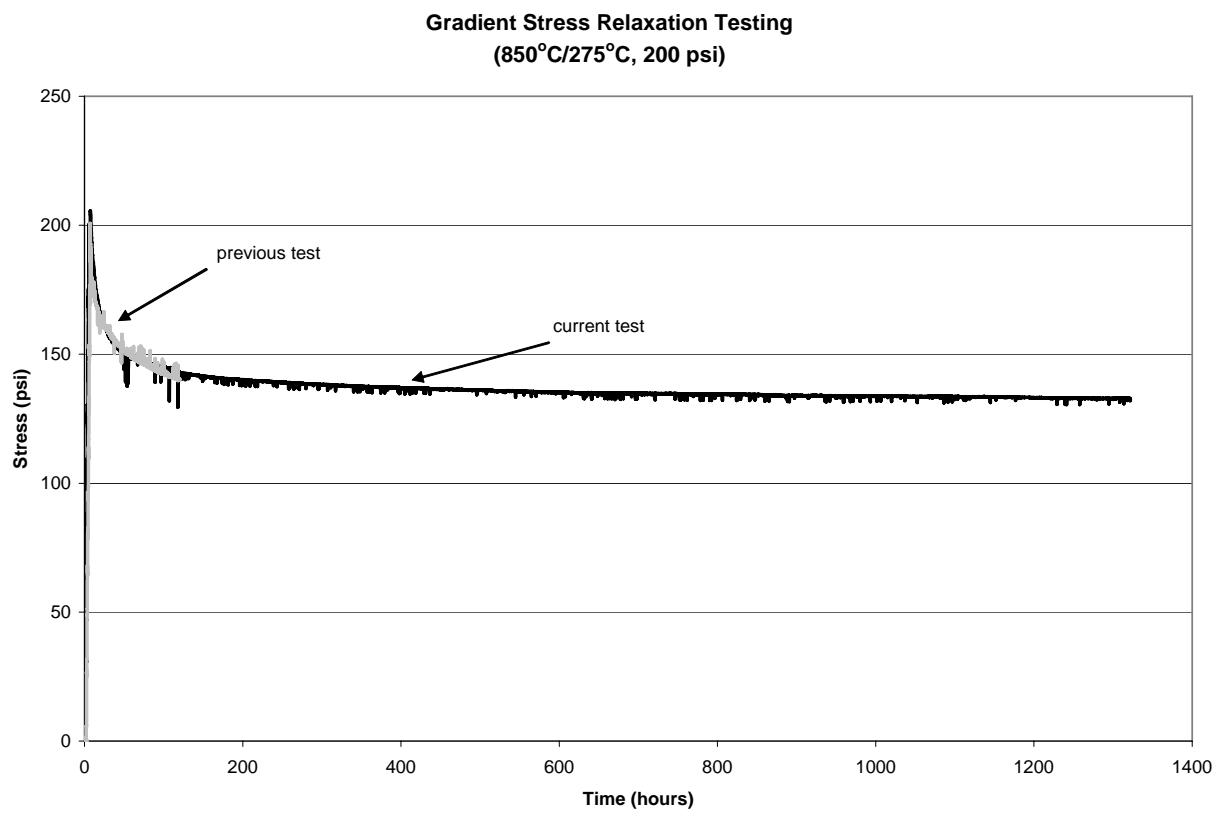

Figure 10. Typical Result from Gradient Stress Relaxation Testing

The data shown from the isothermal testing demonstrates the two types of behavior seen between the two regimes of temperature (high and low). This difference in behavior necessitated the additional isothermal testing at 650 and $550^{\circ} \mathrm{C}$.

High temperature compression testing has been completed. Typical results from testing are shown in Figure 11. 

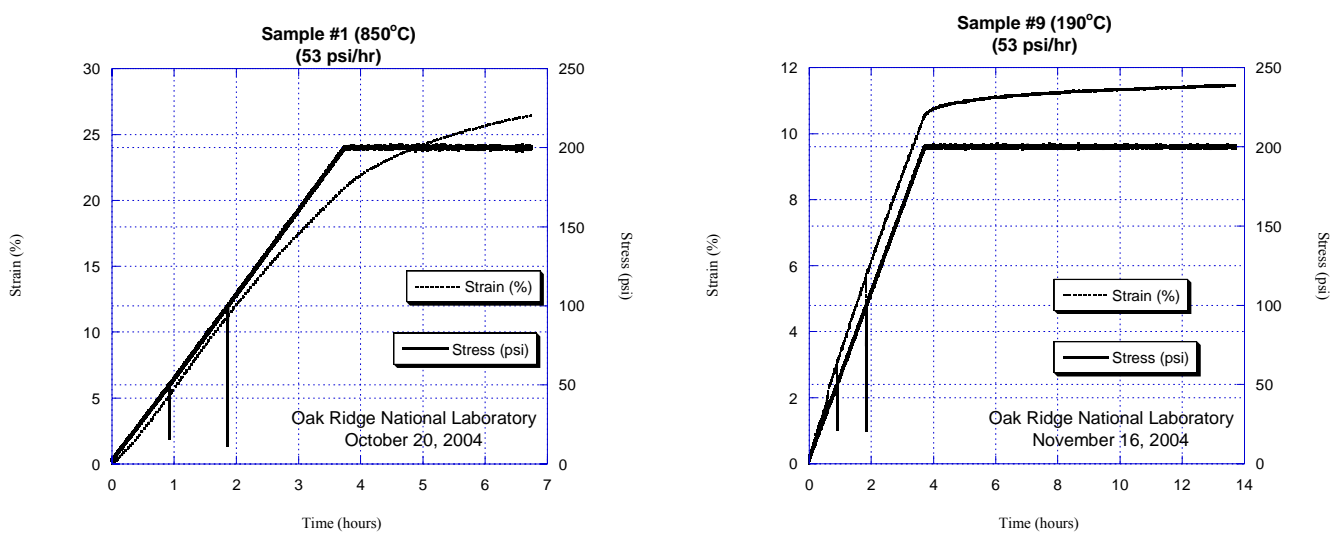

Figure 11. Typical Results from High Temperature Compression Testing

In support of the analysis of the mechanical testing results, other testing and evaluation of the Min-K material was pursued. This testing and evaluation included measurement of elastic modulus and thermal conductivity, along with SEM/EDS analysis. Examples of results from this testing are shown in Figure 12 and Figure 13.

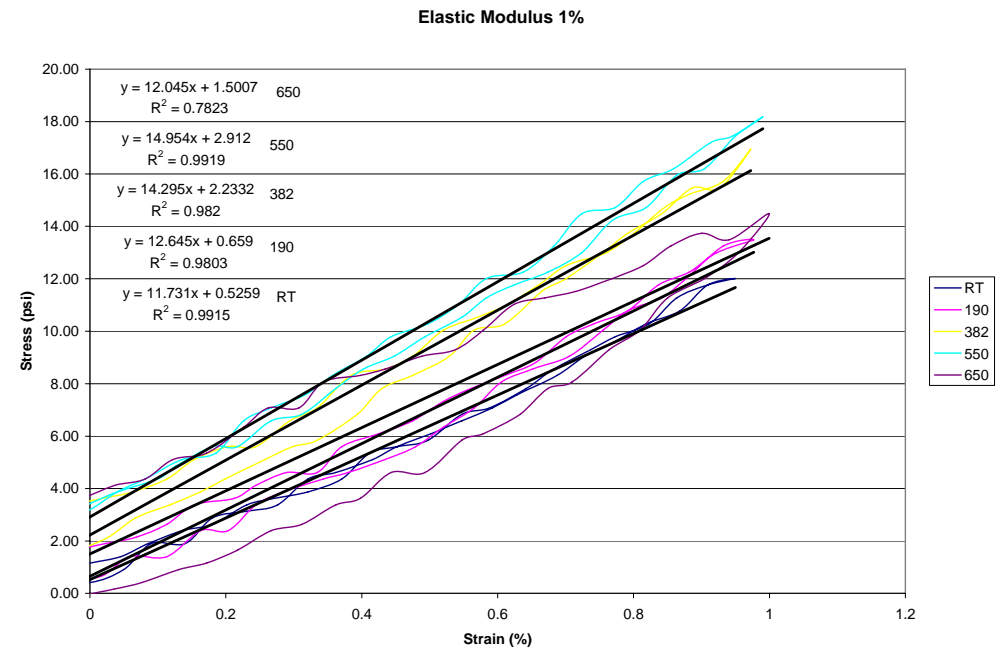

Figure 12. Typical Results from High Elastic Modulus Testing
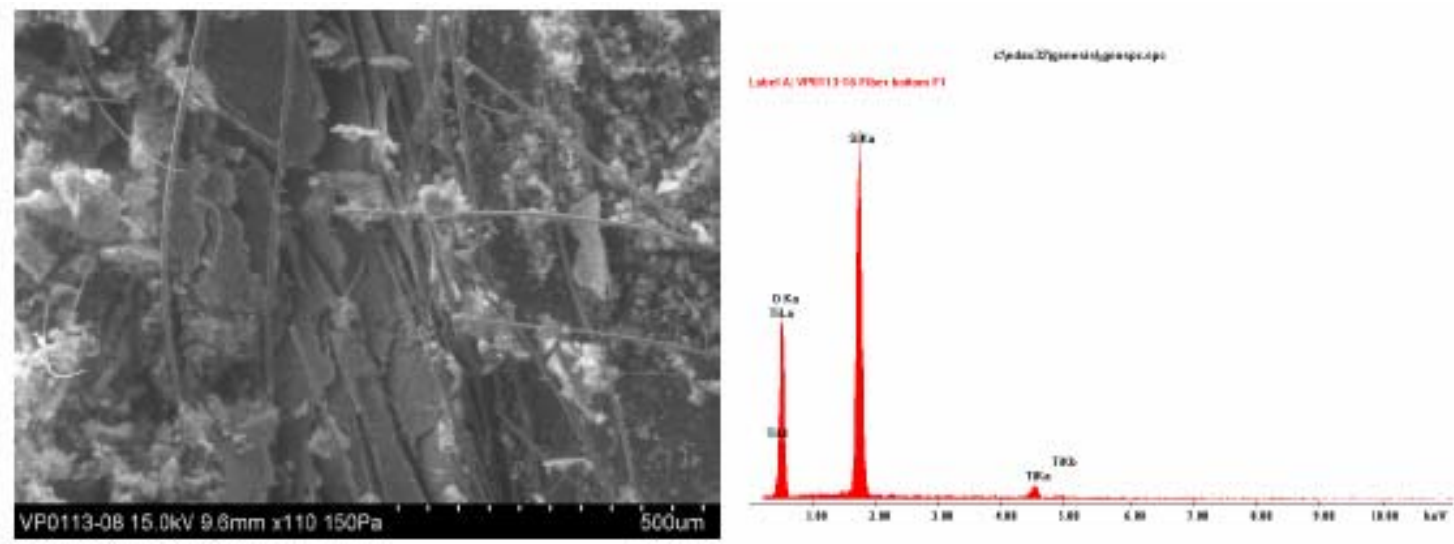

Figure 13. Typical Results from SEM/EDS Analysis 
Model formulation was initially performed based on all collected isothermal data. The stress relaxation of Min-K at temperatures between $190^{\circ} \mathrm{C}$ and $850^{\circ} \mathrm{C}$ was described by the following equation:

$$
\frac{\sigma(t)}{\sigma_{o}}=a_{1} e^{-\frac{t}{t_{1}}}+a_{2} e^{-\frac{t}{t_{2}}}
$$

where $\sigma$ is the compressive stress, $\sigma_{o}$ is the original stress (either 100 or $200 \mathrm{psi}$ ), $t$ is time, $a_{l}$ and $a_{2}$ are temperature-dependent parameters and $t_{1}$ and $t_{2}$ are the relaxation times of the material. Relaxation times were selected arbitrarily so that they would represent the time span over which the model needs to be applicable.

After fitting this model to experimental data, it was found that the constants $a_{i}$ and $t_{i}$ could be expressed as follows, where $\mathrm{T}$ is temperature in ${ }^{\circ} \mathrm{C}$ :

\begin{tabular}{|c|c|}
\hline$A_{1}$ & $0.053+7.6 \times 10^{-10} T^{3}$ \\
\hline$A_{2}$ & $0.88-\left(\frac{T}{880}\right)^{4}$ \\
\hline$T_{1}$ & $10 \mathrm{hrs}$. \\
\hline$T_{2}$ & $10,000 \mathrm{hrs}$. \\
\hline
\end{tabular}

Data from isothermal stress relaxation testing performed at temperatures between 850 and $190^{\circ} \mathrm{C}$ was incorporated into the finite element program ANSYS to model the relaxation behavior of Min-K. It was found that the data at each test temperature could be modeled by using the time hardening creep equation. The form of this model used by ANSYS is:

$$
\dot{\varepsilon}_{c r}=a \sigma^{b} t^{c} e^{\frac{-d}{T}}
$$

where $\dot{\varepsilon}_{c r}$ is the change in creep strain with respect to time, $\sigma$ is equivalent stress, $\mathrm{t}$ is time, $\mathrm{T}$ is temperature, and a, b, c, and d are temperature dependent parameters.

Initial analyses were performed for several isothermal cases to verify the creep model. The material model in ANSYS was applied to a finite element model consisting of 400 axisymmetric elements and 441 nodes. A cylinder with a radius of 3 inches and a height of 3 inches was modeled in ANSYS with the axisymmetric elements. The results of these analyses showed good agreement with test data. Figure 14 shows the comparison between the finite element analysis (FEA) and the test results $190^{\circ} \mathrm{C}, 650^{\circ} \mathrm{C}$, and $850^{\circ} \mathrm{C}$. 

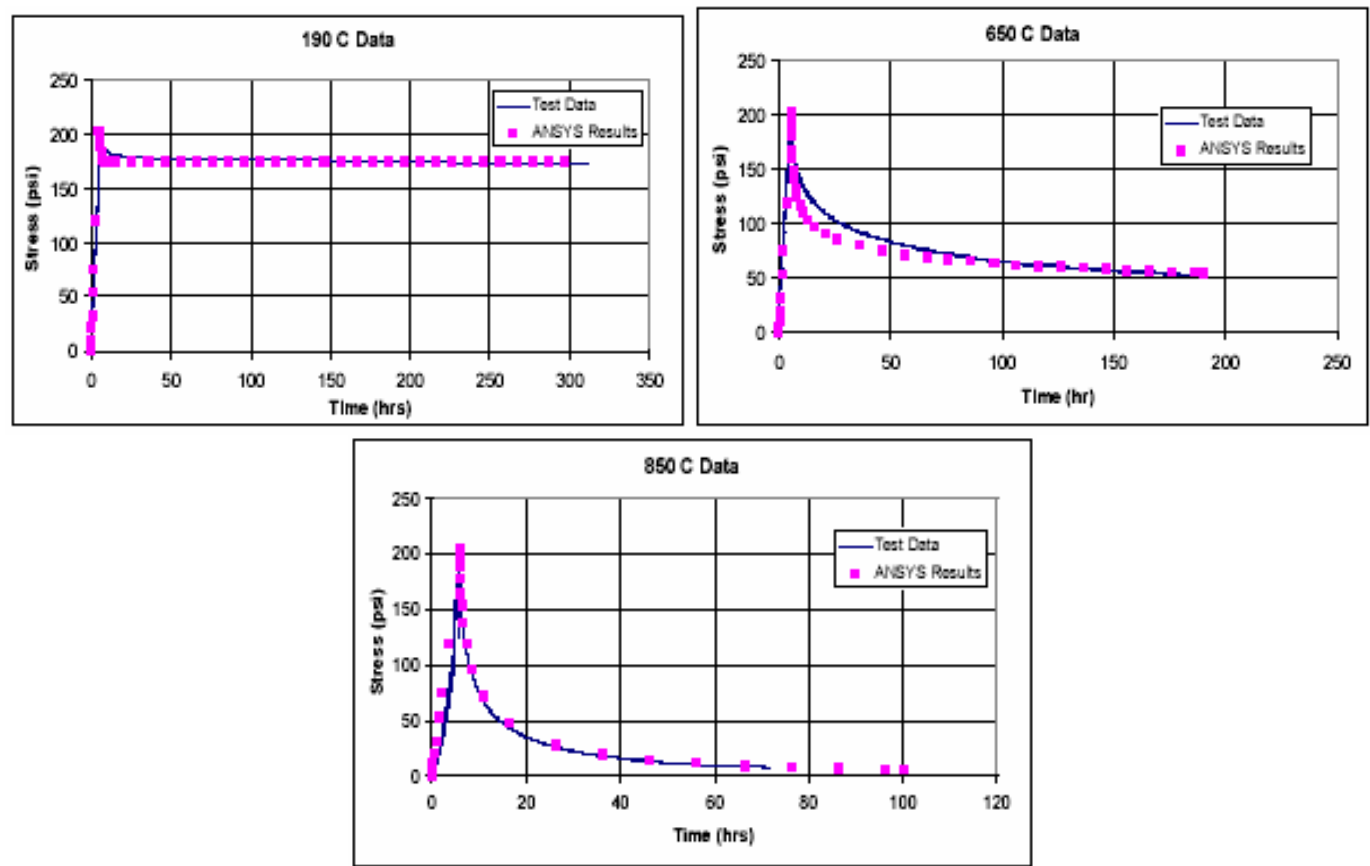

Figure 14. Comparison of Experimental Results and FEA Predictions

After the applicability of the creep model was verified for the isothermal case at different temperatures, the model was used to analyze the case when a temperature gradient is applied to the test specimen. Initial analyses were performed for the case of a uniform gradient along the main axis of the model. The results of this analysis predicted much more stress relaxation than what had been determined experimentally. A temperature gradient more closely matching the actual test temperature distribution during a temperature gradient stress relaxation test was used to repeat the analysis. Figure 15 shows the temperature distribution obtained experimentally along with that predicted by ANSYS through interpolation.

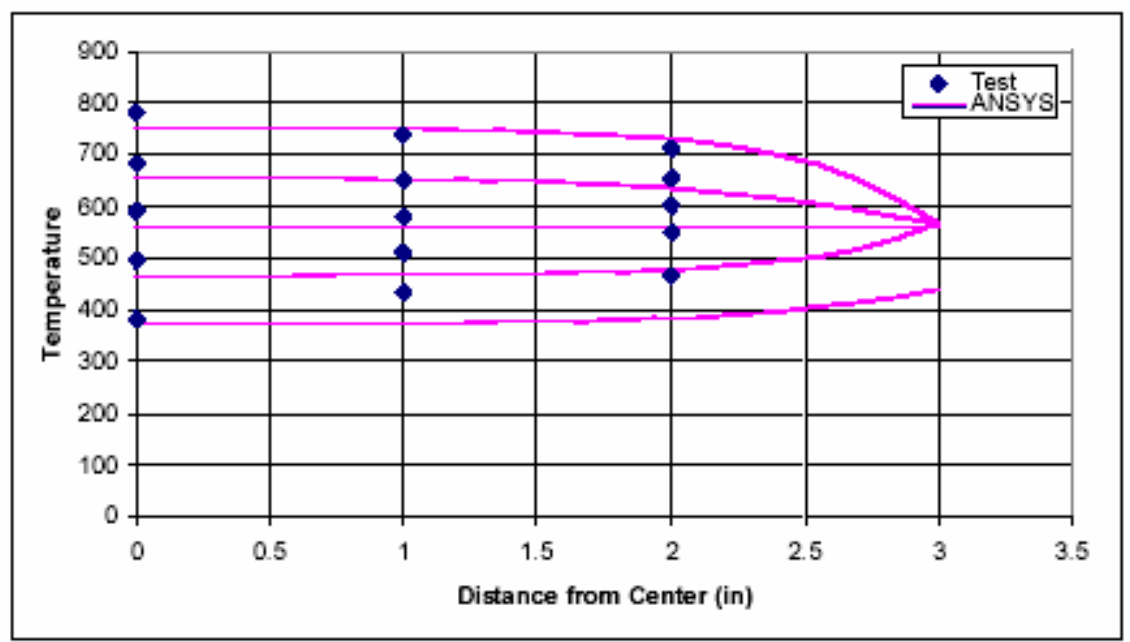

Figure 15. Comparison of Temperature Distributions Determined Experimentally and Extrapolated from FEA Model

At the center of the test specimen the axial temperature gradient is uniform but temperatures away from the center of the test specimen approach the outside temperature of the furnace. The 
results from the thermal FEA model were used as input for the structural model in ANSYS and it was found that the predicted stress relaxation did fit the experimental results much more closely. Figure 16 shows a comparison between the stress predicted by the model and the experimental results for a temperature gradient test under $200 \mathrm{psi}$ at temperatures between $850^{\circ} \mathrm{C}$ and $275^{\circ} \mathrm{C}$.

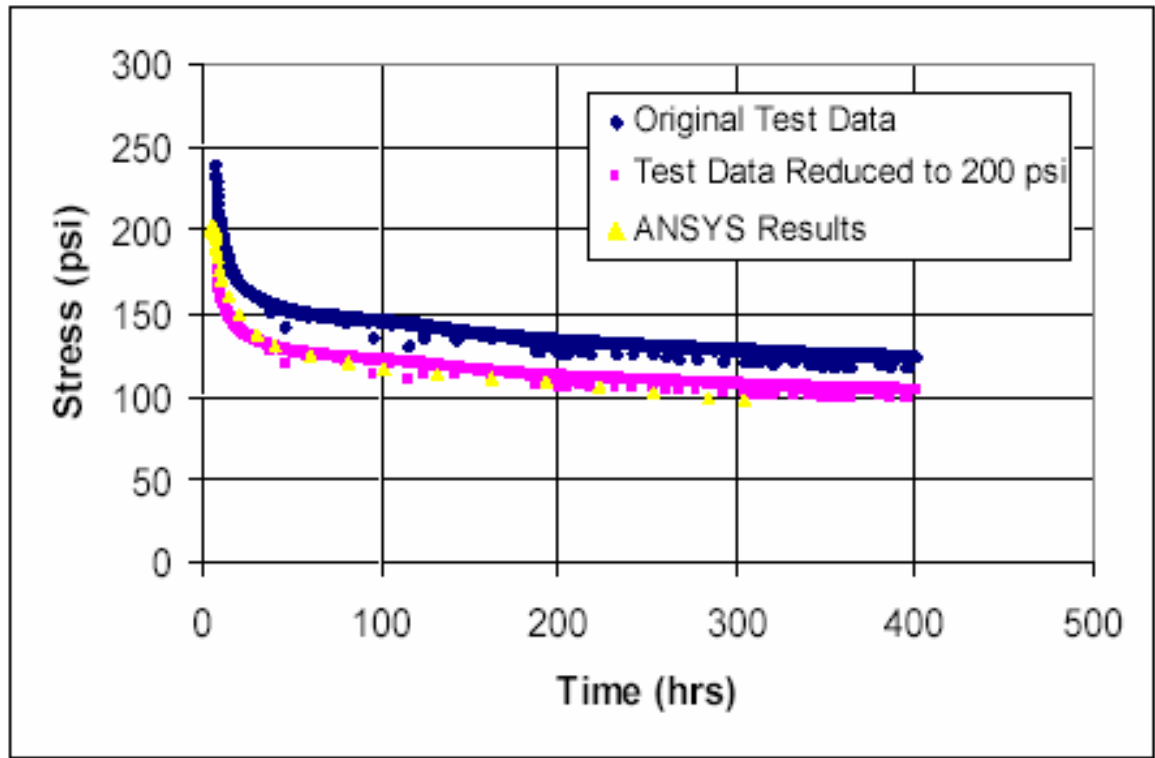

Figure 16. Comparison of Experimental Data and FEA Predictions

The proposed closed-form solution was found to be described by the equation:

$$
\begin{aligned}
& \mathrm{m} 1 \operatorname{Exp}(-\mathrm{t} / 10)+\mathrm{m} 2 \operatorname{Exp}(-\mathrm{t} / 200)+\mathrm{m} 3 \operatorname{EXP}(-\mathrm{t} / 10000) \\
& \text { where: }\left(\begin{array}{l}
\text { for } \left.\mathrm{T}>382^{\circ} \mathrm{C}\right) \\
\mathrm{m} 1=0.0011 \mathrm{~T}-0.34 \\
\mathrm{~m} 2=1.09 \mathrm{E}-8 \mathrm{~T}^{3}-2.4 \mathrm{E}-5 \mathrm{~T}^{2}+0.0176 \mathrm{~T}-3.7 \\
\mathrm{~m} 3=2.8 \mathrm{E}-6 \mathrm{~T}^{2}-0.0053 \mathrm{~T}+2.482 \\
\left(\text { for } \mathrm{T} \leq 382^{\circ} \mathrm{C}\right) \\
\mathrm{m} 1=0.08 \\
\mathrm{~m} 2=0.014 \\
\mathrm{~m} 3=0.86
\end{array}\right.
\end{aligned}
$$

Examples of test data fit with this equation are shown in Figure 17.
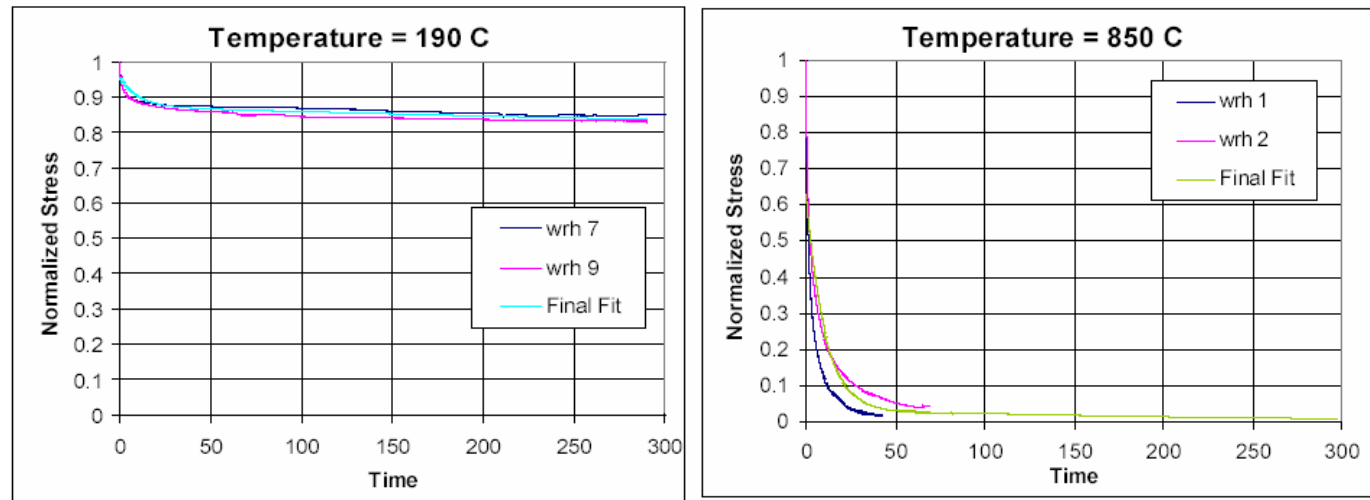

Figure 17. Typical Results from Fitting of Closed Form Model 


\subsubsection{Summary of Min-K Testing}

Preliminary compression testing at room temperature was performed on hour-glass and cylindrical geometry samples to determine optimum size geometry, and loading rate for subsequent testing. The key finding from this testing was that cylindrical samples were appropriate for subsequent testing due to the ease of sample fabrication and the simplified data analysis as compared to the hour glass sample geometries. Additionally, the data obtained using the cylindrical geometry samples was comparable to those obtained with the two hour glass geometries after correction for effects of these geometries was made (i.e. correction for neck portions of samples and non-uniform cross section of samples).

Preliminary high temperature compression testing was performed on cylindrical specimens (2" diameter, 3" length) to determine loading rates for subsequent testing. The key results from this testing were the determination of loading schemes for subsequent stress relaxation testing and high temperature compression testing. It was determined that stress relaxation samples would be loaded in strain control utilizing a 12 step loading scheme with loading every half hour at a rate of $5.56 \%$ strain/hour. High temperature compression samples were loaded in load control at a rate of $53 \mathrm{psi} /$ hour followed by a hold of 3-100 hours in load control to allow for sample creep.

Five mechanical testing frames were modified to accommodate elevated temperature compression testing of Min-K samples and both isothermal and gradient-temperature stress relaxation testing in a controlled helium environment. Special heated platens were designed and constructed for the gradient-temperature stress relaxation testing. Isothermal and gradient stress relaxation testing has been performed along with high temperature compression testing. High temperature compression testing, isothermal stress relaxation testing, and gradient stress relaxation testing, as defined in the original test matrix, have been completed. Additional isothermal stress relaxation testing has also been performed at intermediate temperatures and additional long-term (6 month or greater) gradient stress relaxation testing has been requested. Additionally, model formulation has been performed based on isothermal test data and extended to the gradient case. An original mathematical formulation was found, an ANSYS based model was formulated and a closed form solution was attempted. Further extension of the models will be pursued.

Additionally, the feasibility of performing long-term (6 month or greater) compressive creep testing has been evaluated along with costs and facility obligations. 
Appendix 1

Min-K Testing and Characterization

Test Matrix: Preliminary Compression Tests

(Hour-Glass Specimen Geometries)

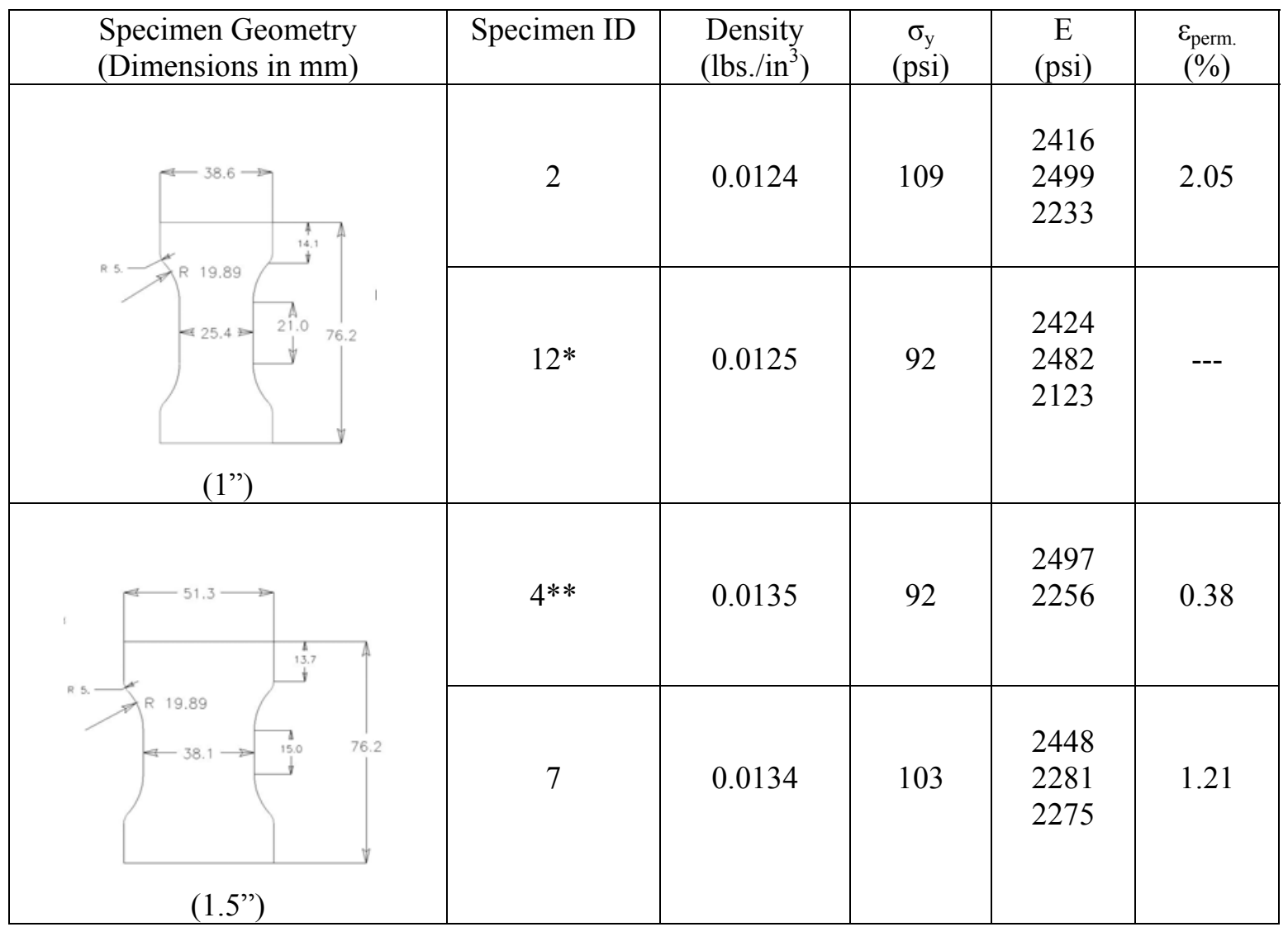

* run to very high loads (and failure) when wrong test program was used

** only run to $150 \mathrm{psi}$ ( 2 loading cycles) before test was prematurely ended 
Min-K Testing and Characterization

Test Matrix: Preliminary Compression Tests

(Hour-Glass Specimen Geometries)

\begin{tabular}{|c|c|c|c|c|c|}
\hline $\begin{array}{l}\text { Specimen Geometry } \\
\text { (Dimensions in } \mathrm{mm} \text { ) }\end{array}$ & $\begin{array}{c}\text { Specimen } \\
\text { ID }\end{array}$ & $\begin{array}{l}\text { Density } \\
\left(\text { lbs./in }^{3}\right)\end{array}$ & $\begin{array}{c}\sigma_{\mathrm{y}} \\
(\mathrm{psi})\end{array}$ & $\begin{array}{c}\mathrm{E} \\
(\mathrm{psi})\end{array}$ & $\begin{array}{l}\varepsilon_{\text {perm. }} . \\
(\%)\end{array}$ \\
\hline & 1 & 0.0121 & 96 & $\begin{array}{l}2219 \\
2131 \\
1984\end{array}$ & 1.93 \\
\hline 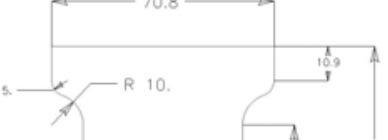 & 3 & 0.0123 & 96 & $\begin{array}{l}1880 \\
1857 \\
1853 \\
\end{array}$ & 1.41 \\
\hline $450.8 \longrightarrow \underset{\substack{4 \\
26.2}}{\downarrow}$ & 5 & 0.0123 & 118 & $\begin{array}{l}2259 \\
2348 \\
2013\end{array}$ & 1.46 \\
\hline \multirow[t]{2}{*}{ (2" Configuration a) } & 10 & 0.0130 & 91 & $\begin{array}{l}3527 \\
3370 \\
3342\end{array}$ & 0.82 \\
\hline & 13 & 0.0126 & 105 & $\begin{array}{l}2253 \\
2191 \\
1885\end{array}$ & 0.77 \\
\hline
\end{tabular}


Min-K Testing and Characterization

Test Matrix: Preliminary Compression Tests

(Hour-Glass Specimen Geometries)

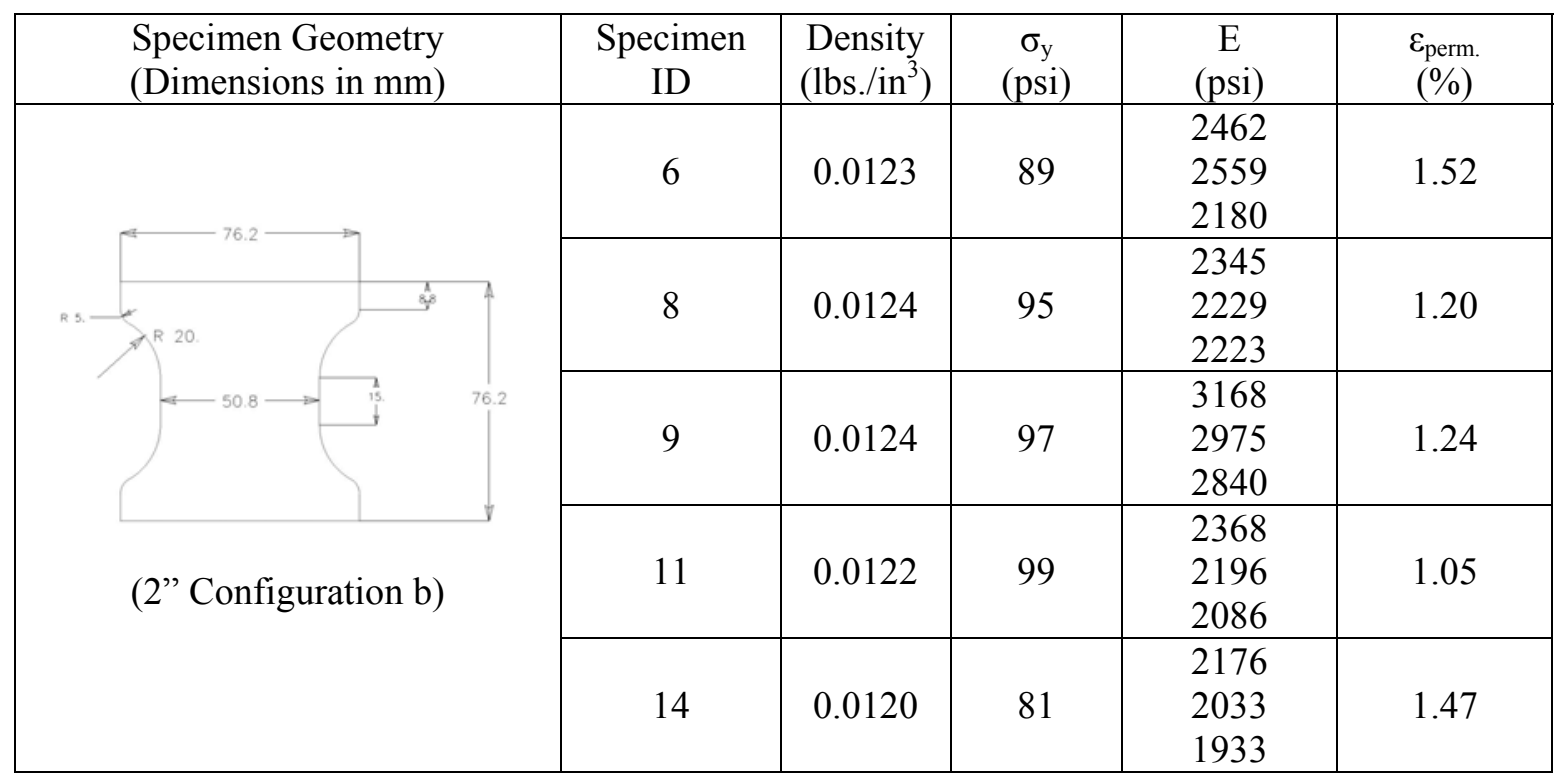


Min-K Testing and Characterization

Test Matrix: Preliminary Compression Tests

(Cylindrical Specimen Geometries)

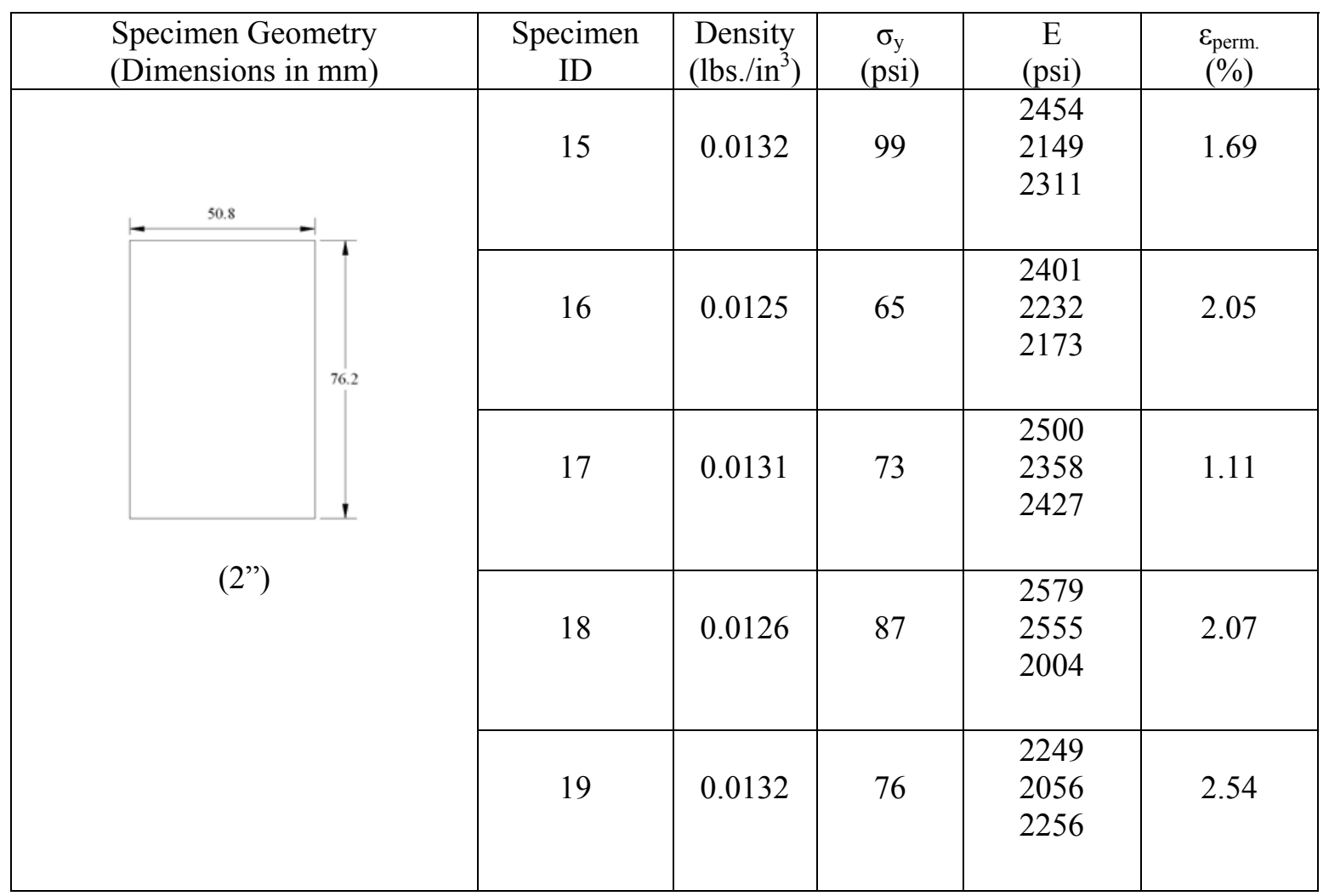

